\title{
Team boundary work and team workload demands: Their interactive effect on team vigor and team effectiveness
}

\author{
Ulrich Leicht-Deobald ${ }^{1}$ (c) | Chak Fu Lam ${ }^{2}$ | Heike Bruch ${ }^{1}$ | Florian Kunze ${ }^{3}$ | \\ Wen $\mathrm{Wu}^{4}$
}

${ }^{1}$ University of St.Gallen, St. Gallen, Switzerland

${ }^{2}$ City University of Hong Kong, Hong Kong, China

${ }^{3}$ University of Konstanz, Konstanz, Germany

${ }^{4}$ Management Department, School of Economics and Management, Beijing Jiaotong University, Beijing, China

\section{Correspondence}

Wen Wu, Management Department, School of Economics and Management, Beijing Jiaotong University, No. 3 Shangyuan Cun, Beijing 100044, China.

Email: wuwen@bjtu.edu.cn

\section{Funding information}

This work was supported by City University of Hong Kong (Grant \#7200545) to Dr. Chak Fu LAM.; Basic Research Funds of University of St.Gallen, Grant/Award Number: 1031501

\begin{abstract}
Drawing from team-level job demands-resources theory, we hypothesize that team workload demands moderate the positive link between team boundary work (i.e., boundary spanning and boundary buffering) and team effectiveness (i.e., team innovation and team performance), such that boundary work is more beneficial for team effectiveness when teams face higher team workload demands. Furthermore, we predict that this interaction occurs through increased team vigor, where team vigor is defined as an affective emergent state characterized by positive valences and high activation levels experienced by team members. We largely find support for our model across two field studies: a cross-sectional survey using three independent data sources (89 automotive research and development teams, including 724 team members, 89 team leaders and 18 managers) and a time-lagged survey using two independent data sources (139 teams working in a Chinese utility company, including 640 team members and 139 team leaders). Our article contributes to team research by broadening our understanding of when and how team boundary work is associated with greater team effectiveness.
\end{abstract}

\section{KEYWORDS}

boundary buffering, boundary spanning, team boundary work, team innovation, team performance, team vigor, team workload demands

\section{1 | INTRODUCTION}

As organizations become more hierarchically flat (Faraj \& Yan, 2009), self-organized (Yan \& Louis, 1999), and networkoriented than ever before (Cross et al., 2000; de Vries et al., 2014), one topic of debate is how teams can meet the resulting challenges through team boundary work, which is defined as team activities that establish and maintain team boundaries as well as manage interactions across those boundaries (Marrone, 2010). The extant research on teams shows that team boundary work is positively associated with various measures of team effectiveness, such as team performance (Ancona \& Caldwell, 1992; Gibson \& Dibble, 2013), market performance (Morgan \& Piercy, 1998), project and product quality (Haas, 2006), team efficacy (Keller, 2001), team and stakeholder satisfaction (Marrone et al., 2007), and team innovation (Somech \& Khalaili, 2014).

Although a large body of research supports the existence of this positive link between boundary work and team effectiveness (see Dey \& Ganesh, 2017, and Marrone, 2010, for reviews), research examining the boundary conditions of this association is lacking (see Cummings, 2004

This is an open access article under the terms of the Creative Commons Attribution-NonCommercial-NoDerivs License, which permits use and distribution in any medium, provided the original work is properly cited, the use is non-commercial and no modifications or adaptations are made.

(c) 2022 The Authors. Human Resource Management published by Wiley Periodicals LLC. 
Faraj \& Yan, 2009; Gibson \& Dibble, 2013, for exceptions). Prior research has indicated that teams differ markedly in the extent to which they benefit from boundary work (Choi, 2002; Joshi et al., 2009) with some empirical studies showing nonsignificant (Haas, 2006; Lewis et al., 2002; Sawyer et al., 2010) or even negative relationships (Atuahene-Gima, 2003; Hansen, 1999; Katz, 1982) between boundary work and team effectiveness. Although boundary work offers significant advantages for most teams (Cummings, 2004; de Vries et al., 2014; Marrone et al., 2007), it may create labor-intensive disturbances in core team tasks for others. In such cases, a team may experience reduced or no positive effects of boundary work (Gibson \& Dibble, 2013; Hansen, 1999; Katz, 1982; Kianto, 2011; Sawyer et al., 2010) because the activities associated with this work require substantial time and effort and may, thus, distract the team from its primary tasks (Faraj \& Yan, 2009; Gibson \& Dibble, 2013; Haas, 2006). Hence, the benefits of boundary work may not manifest across all teams.

Furthermore, while the majority of studies find a positive relationship between boundary work and team effectiveness (Ancona \& Caldwell, 1992; Dey \& Ganesh, 2017; Joshi et al., 2009), the mechanisms behind this positive association are not fully understood and the results are equivocal. For example, Faraj and Yan (2009) theorize that boundary work creates a sense of psychological safety, defined as the extent to which team members feel they can take interpersonal risks and speak up without punishment (Edmondson, 1999), and that this, in turn, contributes to team effectiveness. However, contrary to their hypothesis, the authors find that psychological safety does not mediate the proposed relationship. Moreover, they do not find any other mechanism that explains the effect. Other research has hinted that a more affective motivational mechanism links boundary work and team effectiveness. Marrone et al. (2007), for example, propose that team boundary activities may improve internal team functioning by generating strong, positive emotional bonds among team members. In line with this argument, Ancona (1990) finds in a qualitative study that teams proactively engaging in team boundary activities with external clients report higher levels of excitement than teams that do not engage in such activities. As such, the extant work has hinted at-but has not empirically tested-an affective mechanism that drives the impact of boundary work on team effectiveness.

Thus, our research aims to shed light on the questions of when and how team boundary work is effective. Drawing from team-level job demands-resource (JD-R) theory (Ellis \& Pearsall, 2011; Loi et al., 2016), we examine a critical moderator of the relationship between boundary work and team effectiveness-team workload demands defined as team members' requirement to work hard and under high time pressure (Janssen, 2001; Karasek, 1979; Sacramento et al., 2013). Specifically, we develop theoretically derived hypotheses regarding how team workload demands serve as a boundary condition of the relationship between boundary work and team effectiveness. We predict that when team workload demands are high, boundary work promotes and maintains team vigor, an emergent, affective team state characterized by positive valences and high activation levels (Russell, 1980; Shirom, 2003). ${ }^{1}$ By helping teams acquire and protect resources that support team members in achieving their goals and feel a sense of control and mastery, the combination of boundary work and high team workload demands is related to higher levels of excitement, liveliness, and enthusiasm. In turn, we predict that team vigor is positively associated with two indicators of team effectiveness-team innovation (West \& Wallace, 1991) and team performance (Devine \& Philips, 2001)-because team vigor encourages team members to be more supportive, collaborative, and helpful within the team (Barsade, 2002; Chi et al., 2011). In contrast, when workload demands are low, the acquisition and protection of team job resources through boundary work is not necessary and such work could distract a team from its core tasks (Faraj \& Yan, 2009; Gibson \& Dibble, 2013). Therefore, we expect boundary work in such a situation to be unrelated to team vigor and subsequent team outcomes. Figure 1 offers an overview of our theoretical model.

Our article makes three contributions to the team boundary work and the JD-R literature. First, we identify and test a critical boundary condition-team workload demands-that influences when team boundary work is beneficial for team effectiveness. Moving beyond previous insights into the general effectiveness of boundary work, we respond to Marrone's (2010, p. 931) call for research that examines "at a finer-grained level how teams can most effectively carry out critical boundary spanning processes." This is important because knowledge about moderating factors is limited. In fact, most studies have paid "little attention [...] to exploring contingencies" in the boundary work-team effectiveness relationship (Marrone, 2010, p. 933; see also Choi, 2002; Faraj \& Yan, 2009). Our investigation highlights a crucial, yet neglected, contingency factor-team workload demands-that provides new conceptual and empirical grounds for organizing team boundary-work efforts to yield optimal effectiveness.

Second, we theorize and examine an important mediating mechanism-team vigor-that explains how boundary work translates into higher team effectiveness. In so doing, we unveil an affective motivational mechanism underlying this relationship beyond the psychological-safety effect proposed in prior research (Faraj \& Yan, 2009). Our identification of this mediating mechanism is important because such mechanisms are the theoretical "cogs and wheels" that explain why two variables co-vary and how the parts of a theoretical model relate to one other (Hernes, 1988, p. 74). Moreover, an understanding of the mechanisms underlying the relationship between team boundary work and team effectiveness can help in the design of interventions and the identification of boundary conditions (e.g., team workload demands), thereby offering practical levers for taking advantage of boundary work and designing boundary-work efforts in the most advantageous way.

Finally, our research has implications for JD-R theory. A recent discussion in the JD-R literature at the individual level concerns whether workload demands and resources have independent main effects (referred to as "additive effect") or an interaction effect (referred to as "multiplicative effect"; Gonzalez-Mulé et al., 2021). Specifically, scholars suggest that the additive effect is more prevalent than the multiplicative effect at the individual level (Doef \& Maes, 1999; Gonzalez-Mulé et al., 2021). At the team level, we find support for a multiplicative effect, whereby team workload demands strengthen the association between boundary work, team vigor, and team effectiveness. As such, our research points to the possibility that a multiplicative effect between workload demands and job resources may be more likely at the team level of analysis than at the individual level. 
FIGURE 1 A theoretical model of team boundary work, team workload demands, and team effectiveness

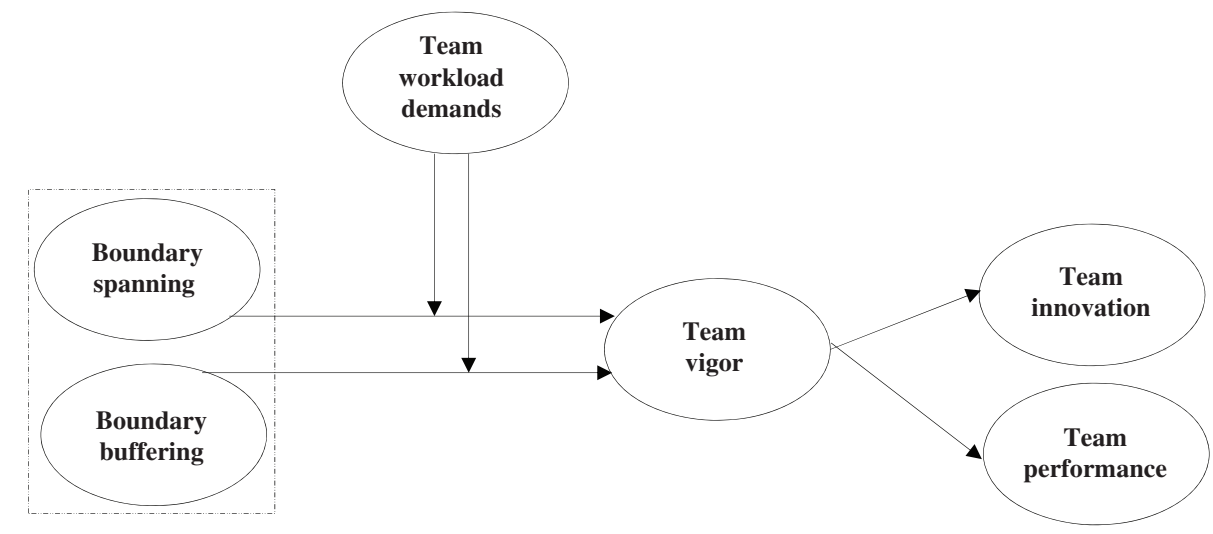

\section{2 | THEORY AND HYPOTHESES}

\subsection{Team boundary work}

Scholars have focused on two types of team boundary work: boundary spanning and boundary buffering (Cross et al., 2000; Faraj \& Yan, 2009; Somech \& Khalaili, 2014). Boundary spanning refers to a team's efforts to manage links with external stakeholders (Ancona \& Caldwell, 1992) by, for instance, seeking crucial information from outside experts, coordinating task activities with external parties, bargaining and negotiating project scope with external stakeholders, building alliances and coalitions with other groups, and managing changing customer requirements (Faraj \& Yan, 2009). Boundary buffering refers to a team's efforts to deal with external requests (Cross et al., 2000). It includes, for instance, monitoring the information and resources that external stakeholders request, sealing off the productive core of team activities, and reducing variability in inputs and outputs in order to allow the team to work free of interferences (Yan \& Louis, 1999). Studies show that both boundary spanning and boundary buffering are positively related to team innovation (Edmondson, 2003; Somech \& Khalaili, 2014) and team performance (Bresman, 2010; Gibson \& Dibble, 2013). We conceptualize team boundary work as an upstream driver of resources but not as a resource per se. As such, boundary spanning and boundary buffering are complementary team processes-boundary spanning increases the resources available to the team, while boundary buffering protects that pool of resources.

According to the team input-process-output model (Marks et al., 2001, p. 357), team boundary work can be conceptualized as a team process, defined as "the means by which members work interdependently to utilize various resources, such as expertise, equipment, and money, to yield meaningful outcomes." The input-processoutput model further suggests that team processes, such as boundary work, should be distinguished from emergent team states-the evolving cognitive, emotional, and affective qualities of a team (e.g., team vigor) that "vary as function of team context, inputs, processes, and outcomes" (Marks et al., 2001, p. 357).

Furthermore, we adapt the job-resource definition of individuallevel JD-R theory to the team level. Specifically, team job resources are those physical, social, psychological, or organizational aspects of the team's tasks that intrinsically and extrinsically motivate team members by helping them collectively achieve their work goals and team tasks (Crawford et al., 2010; Demerouti et al., 2001). ${ }^{2}$ Individuallevel JD-R research has demonstrated that vigor is a core motivational mechanism that explains how (and why) individuals' job resources positively influence important outcomes, such as innovation (Hakanen et al., 2008), personal initiative (Salanova \& Schaufeli, 2008), and task performance (Breevaart et al., 2016; for an overview, see Schaufeli \& Taris, 2014). Similar to prior team-level JD-R research (Ellis \& Pearsall, 2011; Loi et al., 2016), our team-level extension of JD-R theory is based on the assumption of functional equivalence across levels of analysis (Morgeson \& Hofmann, 1999). Specifically, we expect the relationships from JD-R theory to be similar across levels.

\section{2 | Team boundary work and team vigor}

\subsubsection{Boundary spanning and team vigor}

We propose that boundary spanning is positively associated with team vigor for two reasons. First, boundary spanning helps a team gain additional job resources from its external environment. These resources can be material, such as financial resources or equipment (Ancona, 1990), or immaterial, such as project time or professional feedback (Marrone et al., 2007). Furthermore, a boundary-spanning team can make use of its members' informal social networks to acquire and take advantage of external job resources by drawing from their different professional and social backgrounds (Reagans \& Zuckerman, 2001). For instance, when a team member needs specific information, boundary spanning can help establish a relationship with an external party that may be able to provide such resource (Bresman, 2010). Consequently, a team engaging in more boundary spanning can more easily access external knowledge and resources, which is associated with lower uncertainty regarding the team's external inputs (Scott, 1998; Yan \& Louis, 1999). Therefore, we expect more boundary spanning to be associated with higher levels of enthusiasm, liveliness, and excitement about working on team tasks (i.e., more team vigor). 
Second, boundary spanning makes additional job resources available by helping team members influence important constituents both inside and outside of their organization. Such politically influencing activities may include building alliances and coalitions (Marrone, 2010), bargaining about the distribution of important resources (Ancona, 1990), seeking information regarding the organization's political and strategic terrain (Cross et al., 2000), presenting the team's accomplishments in a favorable light (Ancona \& Caldwell, 1992), negotiating delivery deadlines for inputs and outputs in a productdevelopment process (Faraj \& Yan, 2009), and gathering product feedback from customers (Ancona, 1990; Joshi et al., 2009). These activities help teams establish mutually beneficial and trusting relationships with important stakeholders. By gaining access to such external job resources through more boundary spanning, team members can successfully navigate and coordinate their team tasks (Richter et al., 2006) as well as obtain more external support, which reduces their uncertainty about external stakeholders' expectations (Cross et al., 2000; Friedlander, 1987). Therefore, we expect boundary spanning to be positively associated with team vigor:

Hypothesis 1a. Boundary spanning is positively associated with team vigor.

\subsection{2 $\quad$ Boundary buffering and team vigor}

While boundary spanning increases the extent and breadth of team job resources and reduces reducing a team's uncertainty regarding external inputs, boundary buffering protects team job resources and removes external pressures in two ways. First, boundary buffering helps a team reject external requests when those requests are not legitimate or may take away team job resources (Ancona $\&$ Caldwell, 1988). This shields the team from external distractions and interruptions (Faraj \& Yan, 2009). Second, boundary buffering protects important team job resources by reducing political pressures from critical stakeholders (Ancona, 1990). Most organizational teams operate in an environment in which stakeholders, such as upper management or other teams, attempt to shape the micropolitical agenda and influence parties to conform to their best interests (Ancona \& Caldwell, 1992). In this micro-political environment, boundary buffering helps a team reduce political pressure by molding the opinions of those stakeholders and negotiating deadlines, project scope, and priorities (Cross et al., 2000). Higher levels of boundary buffering may also help prevent the spread of negative feelings generated through conflict with external stakeholders, thereby shielding a team's attentional and emotional resources and helping the team remove, deflect, or minimize irrelevant obstacles, pressures, and issues unrelated to its tasks (Thompson, 1967; Yan \& Louis, 1999), contributing to higher team vigor. In sum, we hypothesize:

Hypothesis 1b. Boundary buffering is positively associated with team vigor.

\subsection{3 | The moderating effect of team workload demands}

Although numerous empirical studies have illustrated a positive relationship between team boundary work and team effectiveness (Bresman, 2010; DeChurch \& Marks, 2006; Marrone et al., 2007), other research has found that boundary work yields tangible problems-and costs-that may attenuate its resource advantages (Choi, 2002; Haas, 2006), resulting in nonsignificant (Haas, 2006; Lewis et al., 2002; Sawyer et al., 2010) or even negative relationships (Atuahene-Gima, 2003; Hansen, 1999; Katz, 1982). A core notion in this perspective is that boundary work is effortful and time-consuming and, thus, may distract a team from its internal activities and goals (Gibson \& Dibble, 2013; Haas, 2006; Sleep et al., 2015).

In this regard, an important characteristic of JD-R theory is the concept of job demands. According to this theory, job demands, such as time pressure or work overload, can enhance the benefit of job resources. This is because the combination of job resources and job demands can create a sense of challenge and stimulation, as people may experience a sense of control and mastery in such situations (Crawford et al., 2010; N. P. Podsakoff et al., 2007). ${ }^{3}$ Bakker et al. (2010, p. 3), for example, argue that "enjoyment and commitment will be highest when employees are confronted with challenging and stimulating tasks, and have sufficient resources at their disposal." In extending these insights to the team level, Ellis and Pearsall (2011) introduce a team-training program designed to provide job resources by giving team members information regarding their teammates' roles and responsibilities. They find that when team workload demands are high, the team-training program decreases tensions among team members, increases mental-model accuracy, and enhances information allocation among team members. In contrast, when team workload demands are low, this type of training does not offer a resource advantage.

\subsection{4 | Moderating effect of team workload demands on the association between boundary spanning and team vigor}

When boundary-spanning team members face high team workload demands, they must garner sufficient resources to meet these demands. As such, by acquiring resources, such as financial and informational support, through boundary-spanning activities, team members can better meet the challenge of high team workload demands (Loi et al., 2016). Moreover, boundary spanning can also help team members influence important stakeholders to better manage such stakeholder relationships, which is especially crucial when team workload demands are high. Therefore, we expect the association between team boundary spanning and team vigor to be more positive when team workload demands are high. In contrast, when team workload demands are low, there is little need for teams to expand their job resources pool. As such, the resources acquired through boundary spanning may not translate into 
tangible assets and may even distract team members from meeting task expectations (Faraj \& Yan, 2009; Gibson \& Dibble, 2013). As a result, we expect boundary spanning to be unrelated to team vigor when team workload demands are low. In sum, we offer the following hypothesis:

Hypothesis 2a. Team workload demands moderate the relationship between boundary spanning and team vigor, such that the relationship is more positive when team workload demands are higher.

\subsection{5 | Moderating effect of team workload demands on the association between boundary buffering and team vigor}

We similarly expect that, when a team faces high workload demands, it is especially important for team members to protect their job resources (Rai, 2018). Due to high team workloads, the protection of team resources becomes especially critical. For example, when team workload demands are high, external requests or political pressures may take away team job resources that are crucial for meeting high team workload demands. As such, when team workload demands are high, boundary-buffering activities become especially crucial to remove, deflect, or minimize irrelevant obstacles, such as preventing interruptions from external constituents, postponing prospective assignments or duties, shielding external requests, or reducing external emotional disturbances (Guinan et al., 1998), thereby maintaining higher team vigor. In contrast, when team workload demands are low, there is little need for a team to protect its resources, and the costs of protecting its resources through boundary buffering may even offset its potential benefits (Haas, 2006; Sherman \& Keller, 2010). As a result, the benefits associated with the protection of team job resources through boundary buffering are unlikely to translate into team vigor. Therefore, we hypothesize the following:

Hypothesis $2 \mathrm{~b}$. Team workload demands moderate the relationship between boundary buffering and team vigor, such that the relationship is more positive when team workload demands are higher.

\subsection{6 | Consequences of team vigor for team effectiveness}

According to JD-R theory, vigor is an important precursor of individual innovative behavior (Hakanen et al., 2008) and performance (Breevaart et al., 2016). Consistent with this perspective, we propose that team vigor is positively related to two indicators of team effectiveness: team innovation and team performance. First, team innovation is "the intentional introduction and application within a team, of ideas, processes, products, or procedures new to the team, designed to significantly benefit the individual, the team, the organization, or wider society" (West \& Wallace, 1991, p. 303). It is characterized by high levels of cognitive and behavioral complexity, as it involves both the development of novel ideas, which requires openness and creativity (Lee et al., 2018; Tu et al., 2019), and the implementation of those ideas, which requires stamina, persistence, and a willingness to act (Forgas \& George, 2001). Team vigor is likely to be particularly critical for these team processes, as research suggests that vigor is likely to enhance both the number of innovative ideas (Atwater \& Carmeli, 2009) and the implementation of those ideas (Christian et al., 2015). Second, team performance refers to the quantity and quality of team outputs (Hackman, 1987; Marrone et al., 2007). We chose team performance as an indicator of team effectiveness because team vigor should excite team members and provide them with additional persistence to perform well on team tasks.

Past research on teams and helping behaviors suggests that team members who share positive affective experiences are more committed to their teams (Chi et al., 2011) and exhibit more helping behaviors (Barsade, 2002) than team members who have not had such experiences. Furthermore, Barsade and O'Neill (2014) find that when team members experience companionate love-feelings of affection, compassion, and tenderness-for teammates, their team is more likely to exhibit higher levels of teamwork and intragroup cooperation. Given these insights, we propose that higher levels of job-related team vigor help team members become more collaborative, which leads to the development and implementation of novel ideas as well as a higher quality and quantity of team outputs. Moreover, owing to the sense of activation, team members should have more stamina and persistence to implement novel ideas and, in general, perform better than in teams with low levels of job-related team vigor (Barsade, 2002; Chi et al., 2011).

Empirical support in this regard comes from research linking group positive affect (a concept related to team vigor), team innovation, and team performance (Barsade \& Knight, 2015). For example, in a laboratory experiment involving 67 temporary undergraduate work groups, Grawitch et al. (2003) found that when teams experience positive affect similar to job-related team vigor, they are more likely to perform better in creative production tasks. Similarly, through an experiment involving 72 preexisting work groups, Rhee (2006) demonstrated that shared positive group affect enhances positive social interactions among team members and, ultimately, increases team creativity. In addition, in a longitudinal field study, Knight (2015) surveyed 381 members of 33 teams participating in an international, team-based competition at a military academy. He found that positive group affect is associated with more team experimentation, novel ideas, and innovative approaches to tasks. This empirical work at the team level is further supported by individual-level research suggesting that positive affect encourages a cognitive processing style that is characterized by high levels of playfulness and creativity as well as a willingness to explore novel ideas, processes, and solutions, all of which contribute to innovation (e.g., Madrid et al., 2014, 2016). Finally, in a meta-analysis that included 39 primary studies, Knight and 
Eisenkraft (2015) reported a positive association between group positive affect and team performance. In sum, we hypothesize:

Hypothesis 3 ( $3 \mathrm{a}$ and $3 \mathrm{~b})$. Team vigor is positively associated with: (a) team innovation and (b) team performance.

Given the overall model that underlies our research, we also specify two moderated mediation hypotheses that link team boundary work, team workload demands, team vigor, and team effectiveness. Specifically, we propose that team workload demands moderate the association between boundary work (i.e., boundary spanning and buffering) and team vigor ( $\mathrm{H} 2 \mathrm{a}$ and $\mathrm{H} 2 \mathrm{~b})$, and that the benefits of team vigor are positively related to both team innovation and team performance ( $\mathrm{H} 3 \mathrm{a}$ and $\mathrm{H} 3 \mathrm{~b}$ ). More specifically, we propose the following conditional indirect effects:

Hypothesis 4 (4a and 4b). Team workload demands moderate the positive mediated relationship between boundary spanning and (a) team innovation and (b) team performance (via team vigor), such that the positive indirect relationship is more pronounced when team workload demands are higher.

Hypothesis 5 ( $5 \mathrm{a}$ and $5 \mathrm{~b}$ ). Team workload demands moderate the mediated positive relationship between boundary buffering and (a) team innovation and (b) team performance (via team vigor), such that the positive indirect relationship is more positive when team workload demands are higher.

\subsection{Overview of studies}

We tested our theoretical model across two studies comprising two samples from: (a) a multinational automotive firm in Germany and (b) a utility company in China. In Study 1, we examined the effects of team boundary work, team workload demands, and team vigor on team innovation using three separate sources to avoid common method bias. In Study 2, we addressed several limitations of Study 1 by minimizing reverse causality, using team performance as an outcome variable, and conducting our study in China to enhance the generalizability of our model to other cultural settings.

\subsection{Study 1: Methods}

\subsection{1 | Sample and procedure}

We collected data from research and development (R\&D) teams in a multinational automotive company based in Germany. These teams were particularly suitable for our investigation of team boundary work because team members had to work within a highly interconnected, project-based organizational design that involved interaction with the external environment. As such, they had ample opportunities for team boundary work. Team leaders interacted regularly with the team members and were closely involved in task accomplishment. Prior to the data-collection process, the head of the R\&D Department sent emails to all employees, which encouraged their participation in the study and included a link to the questionnaire. The email highlighted the importance of the study for the company and assured the employees of the confidentiality of their responses. Three weeks after the data collection started, the head of R\&D sent a reminder email to nonrespondents. To further motivate participants, we provided each $R \& D$ team with a written report of the results shortly after the survey and offered trainthe-leader workshops to provide team leaders with an opportunity to learn how to lead effectively.

We collected data from three different sources to reduce common method bias (P. M. Podsakoff et al., 2003). First, we gathered surveys on boundary spanning, boundary buffering, and team workload demands from team members. We reasoned that they were the closest to their team boundary activities and team workload demands and, thus, were best suited for evaluating these constructs (Mathieu et al., 2008). Second, we asked the leaders of each team to rate team vigor to allow for a conservative test of the interaction between team boundary activities and team workload demands on team vigor and to avoid a possible common-source bias (P. M. Podsakoff et al., 2003). As team leaders had ongoing interactions with the team members, they represented external agents who had the closest proximity to the team and were, therefore, better suited for providing a more accurate assessment than a self-report. Finally, we gathered data on team innovation from 18 managers on the next hierarchal level who oversaw the team leaders. Each of these managers rated, on average, 4.94 teams $(S D=2.96)$.

\subsection{2 | Sample}

We distributed surveys to 102 teams (1119 team members, 102 team leaders, and 22 managers). Our final sample consisted of 89 teams with matched responses between team leaders and team members (724 team members, 89 team leaders, and 18 managers), resulting in a response rate of $87 \%$ of the teams ( $65 \%$ for team members, $87 \%$ for team leaders, and $82 \%$ for managers). ${ }^{4}$ The mean intrateam response rate was $73 \%$. The majority of team members were male (91\%) and held a university degree (93\%). The average team member was between 36 and 40 years old and had worked for the company for 12.86 years ( $\mathrm{SD}=10.40$ years). Almost all participants' first language was German.

\subsection{3 | Measures}

Unless otherwise stated, all items were captured on a Likert-type scale ranging from (1) "strongly disagree" to (5) "strongly agree." All of the materials were presented in German. Two independent bilingual 
researchers translated the items from English into German and then translated them back into English (Brislin, 1986).

\section{Boundary spanning}

We used a four-item measure developed by Faraj and Yan (2009) to measure team boundary spanning. A sample item is: "To what extent does the team encourage its members to solicit information and resources from elsewhere in and/or beyond the division?" Items were captured using a Likert-type scale ranging from (1) "to a very small extent" to (5) "to a very large extent." One item (i.e., "To what extent does the team depend on information and resources actively solicited by team members, that is, information and resources beyond what comes through official channels?") produced an initially low alpha coefficient of 0.53 for the scale. Hence, we excluded this item from further analysis.

\section{Boundary buffering}

We measured boundary buffering using the four-item scale found in Faraj and Yan (2009). A sample item is: "To what extent are outside pressures deflected or absorbed so that the team can work free of interference?" Items were captured using a Likert-type scale ranging from (1) "to a very small extent" to (5) "to a very large extent."

\section{Team workload demands}

We adapted items from existing measures (Bakker et al., 2003; Beehr et al., 1976) to assess team workload demands in the context of R\&D teams. Our measure comprised three items with the stem "Members of this team ..." and continued as follows: (1) "continuously perform their work under high time pressure," (2) "regularly perform their work at their limits because of their high workloads," and (3) "have so much work to do that they are often overstrained." These items are in line with prior work that conceptualizes high workload and time pressure as challenge demands (Crawford et al., 2010 p. 837).

\section{Team vigor}

We measured team vigor using five items representing positive emotional valence and high activation levels from Van Katwyk et al.'s (2000) job-related affective well-being scale. These five items had the stem "People in my work group..." and continued as follows: (1) "feel excited in their jobs," (2) "feel enthusiastic in their jobs," (3) "feel energetic in their jobs," (4) "feel inspired in their jobs," and (5) "feel ecstatic in their jobs."

\section{Team innovation}

We measured team innovation using a nine-item scale developed by Janssen (2001). This scale built on Kanter's (1988) model of different development stages in the innovation process. Three items referred to idea generation (sample item: "This team creates new ideas for improvement"); three items referred to idea promotion (sample item: "This team mobilizes support for innovative ideas"); and three items referred to idea realization (sample item: "This team transforms innovative ideas into useful applications").

\section{Controls}

We controlled for several factors that might influence team vigor and team innovation. First, we measured team size using archival data on the number of employees per team, as prior research has found larger team size to be associated with more team innovation (Hulsheger et al., 2009). Second, we included a measure of team longevity, which we measured as the average number of years that team members had worked on the team (Katz, 1982). Past research suggests that members with greater longevity are less likely to think critically, less willing to challenge the status quo, and more inclined to adhere to group think, all of which might hinder team innovation (West \& Anderson, 1996). Third, we controlled for demographic team faultlines, or the hypothetical dividing lines that split a team into relatively homogeneous subgroups based on team members' demographic attributes (Thatcher \& Patel, 2012). We calculated demographic faultlines based on the attributes of age and gender using an algorithm developed by Shaw (2004). Prior research has shown that demographic faultlines hinder intrateam communication and, thus, reduce team innovation $(Y$. Chen et al., 2009). Finally, we added team psychological safety as a control variable using Edmondson's (1999) seven-item scale, as prior research has proposed that boundary work enhances the feeling of team psychological safety, which increases team effectiveness (Faraj \& Yan, 2009). Our results hold without the inclusion of the control variables (Becker, 2005; see Table A1).

\subsection{4 | Analytical strategy}

\section{Aggregation statistics}

To justify the aggregation of boundary spanning, boundary buffering, and team workload demand ratings to the team level, we computed within-group interrater agreement ( $r_{\mathrm{wg}}$; James et al., 1993) and intraclass correlation (ICC) values. Boundary spanning had a median $r_{\text {wg }}$ value of 0.74 with ICC $[1,2]$ values of 0.10 and 0.47 , respectively. Boundary buffering had a median $r_{\text {wg }}$ value of 0.77 with ICC $[1,2]$ values of 0.18 and 0.63 , respectively. Team workload demands had a median $r_{\mathrm{wg}}$ value of 0.76 with ICC $[1,2]$ values of 0.25 and 0.72 , respectively. These values provide adequate support for aggregation to the team level (James et al., 1984).

\section{Path modeling with sampling weight procedure}

We conducted our analysis using Mplus 8.4 (Muthén \& Muthén, 1998-2017). Given the nested nature of our data structure (i.e., teams nested within team leaders, who were nested within managers), we employed a sampling weight procedure (referred to as a complex algorithm in Mplus) that adjusted the standard errors of the estimates and the chi-squared statistics of the analysis (Asparouhov, 2006). This sampling weight procedure allowed us to use bootstrapping for the indirect effects, which is not feasible for multilevel models in Mplus (Asparouhov, 2006).

Prior to the analysis, we tested the discriminant validity of our five main variables (i.e., boundary spanning, boundary buffering, team workload demands, team vigor, and team innovation) with a confirmatory factor analysis (CFA) using the same sampling weight procedure 
described above (Asparouhov, 2006). To form three parcels of items as indicators for team innovation, we averaged the three items of each sub-dimension as recommended by Bagozzi and Edwards (1998) The five-factor measurement model exhibited an acceptable fit to the data $\chi^{2}[125]=218.71, p<0.001$; comparative fit index $[C F I]=0.89$, Tucker-Lewis index $[\mathrm{TLI}]=0.86$; root mean square error of approximation [RMSEA] $=0.09$, standardized root mean square residual $[S R M R]=0.08$; see Table $A 2$ ), suggesting that our five variables are empirically distinct. All standardized factor loadings were significant and above 0.40 .

The independent variables were centered on the mean prior to analysis to reduce potential problems of multicollinearity (Aiken \& West, 1991). To check for issues of multicollinearity, we examined the variance inflation factor (VIF) of each independent variable. All VIF values were less than 1.8 , which is well below the cutoff of 10 , indicating that multicollinearity was not a problem in our analysis (Aiken \& West, 1991). Similar to the procedure for regression analysis outlined by Aiken and West (1991), we first specified a path model without the interaction terms to test the main effects (Table 2, Model 1 ). This model was exactly identified (i.e., the number of free parameters exactly equaled the number of known values). Hence, the overall model fit could not be assessed with a chi-squared test. Next, we added the interaction terms to inspect the incremental explained variance of the moderations (Models 2-4). These moderated mediation models were also exactly identified.

\section{Conditional indirect effects}

To test the conditional indirect effects specified in $\mathrm{H} 4 \mathrm{a}$ and $\mathrm{H} 5 \mathrm{a}$, we computed $95 \%$ bias-corrected confidence intervals (Cls) with 1000 bootstrapping resamples of these indirect effects (MacKinnon et al., 2004). An indirect effect $(a \times b)$ is significant at a 0.05 level when the $95 \%$ biascorrected $\mathrm{Cls}$ exclude zero. When assessing indirect effects, bootstrapping techniques are superior to the Sobel test because they are nonparametric and, therefore, do not rely on the assumption of normality, which is generally violated when testing indirect effects (Preacher \& Hayes, 2008). Moreover, we applied the same sampling weight procedure described above to account for the noninterdependence of team innovation ratings (i.e., teams nested within team leaders, who were nested within managers). In this procedure, bootstrapping was calculated separately for each cluster to take the nested nature of the data into account (Asparouhov \& Muthén, 2010).

\section{5 | Study 1: Results}

\subsection{1 | Research model}

Table 1 shows the descriptive statistics, correlations, and alpha coefficients of each variable. $\mathrm{H} 1 \mathrm{a}$ and $\mathrm{H} 1 \mathrm{~b}$ predict that boundary spanning and boundary buffering are positively associated with team vigor, respectively. We tested $\mathrm{H} 1 \mathrm{a}$ and $\mathrm{H} 1 \mathrm{~b}$ with a mediation-only model. As shown in Table 2 (Model 1 ), the coefficients of boundary spanning $(\beta=0.34$, $\mathrm{SE}=0.09, p<0.001)$ and boundary buffering $(\beta=0.31, \mathrm{SE}=0.10$, $p=0.003$ ) were positive and significant. Hence, $\mathrm{H} 1 \mathrm{a}$ and $\mathrm{H} 1 \mathrm{~b}$ are supported.

$\mathrm{H} 2 \mathrm{a}$ predicts that team workload demands moderate the relationship between boundary spanning and team vigor, such that the positive relationship is stronger when team workload demands are higher. As shown in Table 2 (Model 2), the coefficient for the interaction between boundary spanning and team workload demands was positive and significant $(\beta=0.27, \mathrm{SE}=0.08$, $p<0.001$ ). Figure 2 shows the moderating effect of team workload demands on the association between boundary spanning and team vigor. Simple slope analyses revealed that, at high levels of team

TAB LE 1 Descriptive statistics and correlations (Study 1)

\begin{tabular}{|c|c|c|c|c|c|c|c|c|c|c|c|}
\hline Variable & & Mean (SD) & 1 & 2 & 3 & 4 & 5 & 6 & 7 & 8 & 9 \\
\hline \multicolumn{12}{|l|}{ Controls } \\
\hline 1. & Team size & $11.40(5.36)$ & - & & & & & & & & \\
\hline 3. & $\begin{array}{l}\text { Demographic team } \\
\text { faultlines }\end{array}$ & $0.12(0.15)$ & $0.31^{* *}$ & 0.02 & - & & & & & & \\
\hline 5. & Boundary spanning & $3.32(0.36)$ & -0.10 & -0.14 & -0.14 & $0.54^{* * *}$ & $(0.75)$ & & & & \\
\hline 6. & Boundary buffering & $2.81(0.47)$ & 0.04 & -0.07 & -0.06 & $0.38^{* * *}$ & $0.36^{* * *}$ & (0.89) & & & \\
\hline 7. & $\begin{array}{l}\text { Team workload } \\
\text { demands }\end{array}$ & $3.66(0.53)$ & $-0.24^{*}$ & -0.02 & -0.01 & -0.06 & -0.19 & $-0.57^{* * *}$ & (0.93) & & \\
\hline
\end{tabular}

Note: $N=89$ teams. Cronbach's alphas appear in parentheses across the diagonal.

${ }^{*} p<0.05 ;{ }^{* *} p<0.01 ; p<0.001$ (two-tailed). 
TABLE 2 Path model results for team vigor and team innovation (Study 1)

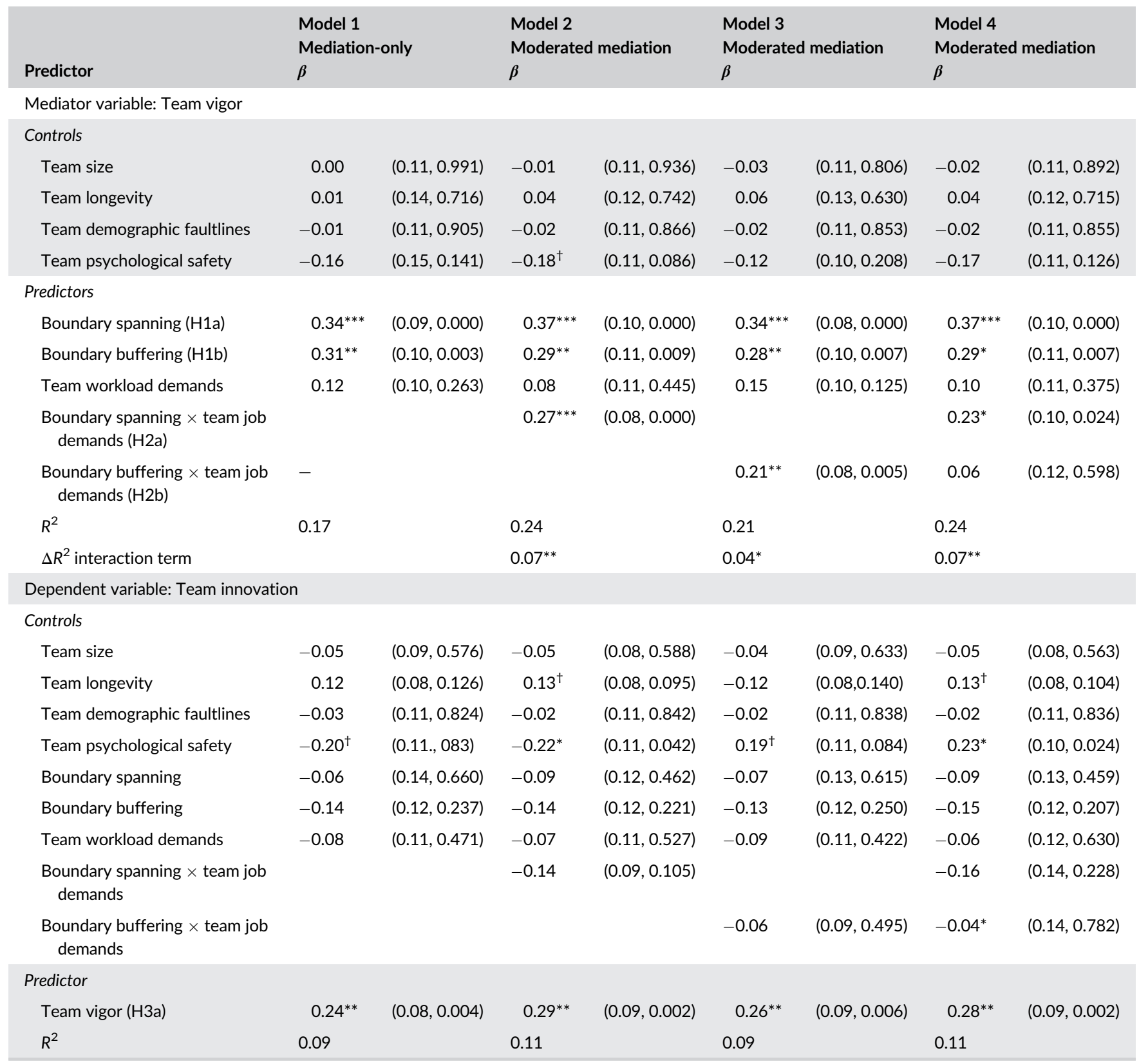

Note: Standardized path coefficients are reported. Values in parentheses are the standard errors and the exact $p$ values.

${ }^{\dagger} p<0.10,{ }^{*} p<0.05,{ }^{* *} p<0.01,{ }^{* * *} p<0.001$ (two-tailed).

workload demands ( $+1 \mathrm{SD}$ ), the slope was positive and significant ( $\beta=0.61, \mathrm{SE}=0.12, p<0.001)$, whereas the slope was not significant $(\beta=0.13, \mathrm{SE}=0.10, p=0.202)$ at low levels of team workload demands ( $-1 \mathrm{SD})$. When compared to the mediation-only model, the explained variance of team vigor significantly increased by $7 \%$ in the moderated mediation model (Table 2, Model 2: $\Delta R^{2}=0.07 ; p=0.008$ ).

In addition, we calculated exact regions of significance for the interaction between boundary spanning and team workload demands using 95\% bias-corrected $\mathrm{Cls}$ and plotted the interaction using a Johnson-Neyman plot (Johnson \& Neyman, 1936) (see Figure 3 ). We found that boundary spanning had a positive and significant relationship with team vigor when the standardized values of team workload demands were -0.60 or higher (the $\beta$ at this transition point was $0.16, \mathrm{Cl}[0.002,0.40]$ ). The strength of the positive association between boundary spanning and team vigor rose to a $\beta$ of $0.95(\mathrm{Cl}[0.52,1.38])$ when team workload demands reached the maximum standardized sample value of 2.54. Moreover, when the standardized values of team workload demands were below -0.60 , boundary spanning had no significant relationship with team vigor. As such, the link between boundary spanning and team vigor was positive and significant for 64 teams (72\%) and not significant for 25 teams (28\%) in our sample. These findings support $\mathrm{H} 2 \mathrm{a}$. 

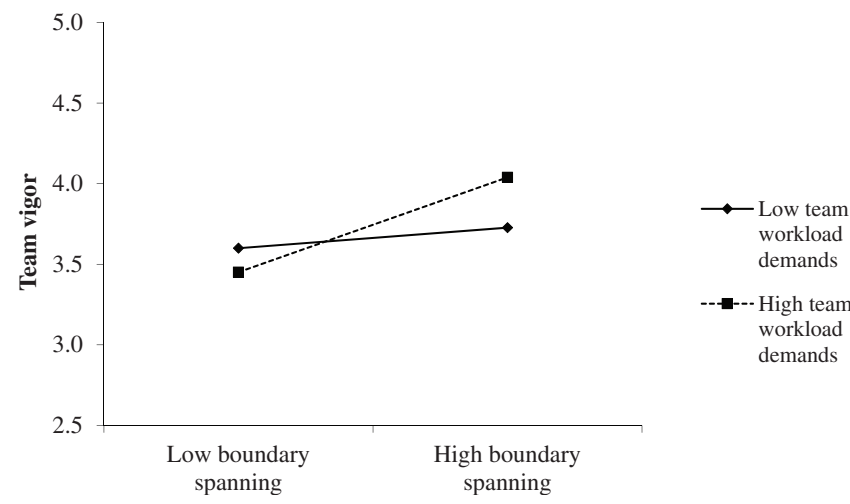

FIGURE 2 Moderating effect of team workload demands on the relationship between boundary spanning and team vigor (Study 1)

$\mathrm{H} 2 \mathrm{~b}$ predicts that team workload demands moderate the relationship between boundary buffering and team vigor, such that the positive relationship is stronger when team workload demands are higher. As shown in Table 2 (Model 3), the coefficient for the interaction between boundary buffering and team workload demands was positive and significant ( $\beta=0.21$, SE $=0.08, p=0.005$ ). Figure 4 shows the moderating effect of team workload demands on the association between boundary buffering and team vigor. Simple slope analyses revealed that, at high levels of team workload demands ( $1 \mathrm{SD})$, the slope was positive and significant $(\beta=0.45, \mathrm{SE}=0.11, p<0.001)$, whereas the slope was not significant $(\beta=0.11, \mathrm{SE}=0.12, p=0.378$ ) at low levels of team workload demands ( $-1 \mathrm{SD})$. When compared to the mediation-only model, the explained variance of team vigor significantly increased by $4 \%$ in the moderated mediation model (Table 2, Model 3: $\Delta R^{2}=0.04, p=0.045$ ).

We also calculated exact regions of significance for the interactions between boundary buffering and team workload demands using 95\% bias-corrected $\mathrm{Cls}$ and plotted the interaction using a JohnsonNeyman plot (see Figure 5). We found that boundary buffering had a positive and significant relationship with team vigor when the standardized values of team workload demands were -0.31 or higher (the $\beta$ at this transition point was $0.22, \mathrm{Cl}[0.002,0.43])$. The strength of

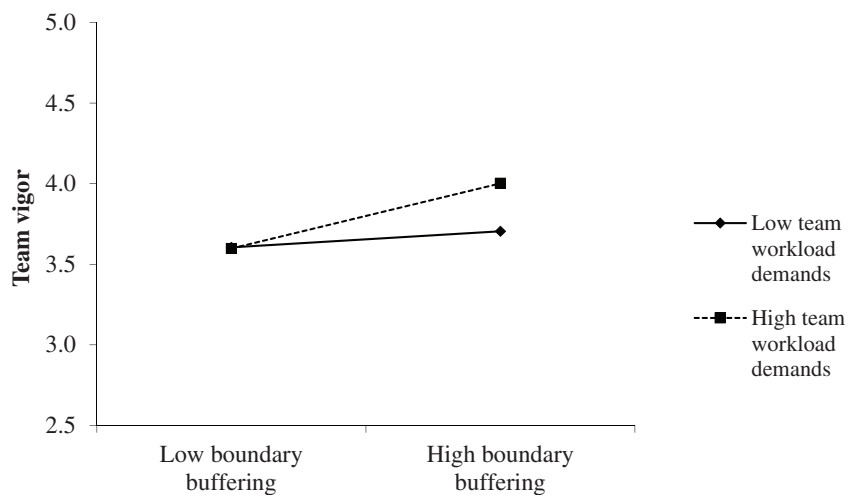

FIGURE 4 Moderating effect of team workload demands on the relationship between boundary buffering and team vigor (Study 1)

the positive association rose to a $\beta$ of $0.77(\mathrm{Cl}[0.44,1.08])$ when team workload demands reached the maximum standardized sample value of 2.54. Moreover, when the standardized values of team workload demands were below -0.31 , team workload demands had no significant relationship with team vigor. As such, the link between boundary spanning and team vigor was positive and significant for 53 teams (60\%) and not significant for 36 teams (40\%) in our sample. These findings support $\mathrm{H} 2 \mathrm{~b}$.

$\mathrm{H} 3 \mathrm{a}$ predicts that team vigor is positively associated with team innovation. As shown in Table 2 (Model 1 ), the effect of team vigor on team innovation was positive and significant $(\beta=0.24, \mathrm{SE}=0.08$, $p=0.004)$. Thus, $\mathrm{H} 3 \mathrm{a}$ is supported.

$\mathrm{H} 4 \mathrm{a}$ predicts that team workload demands moderate the mediated effect of boundary spanning on team innovation through team vigor, such that the positive indirect effect is stronger when team workload demands are higher. As shown in Table 5, when team workload demands were high ( $+1 \mathrm{SD}$ ), the indirect effect through team vigor was positive and significant (high: $a \times b=0.23, \mathrm{Cl}[0.05,0.51]$ ). In contrast, when team workload demands were low (-1 SD), boundary spanning was unrelated to team innovation through team vigor (low: $a \times b=0.05 \mathrm{Cl}[-0.05,0.17]$ ). Thus, $\mathrm{H} 4 \mathrm{a}$ is supported.

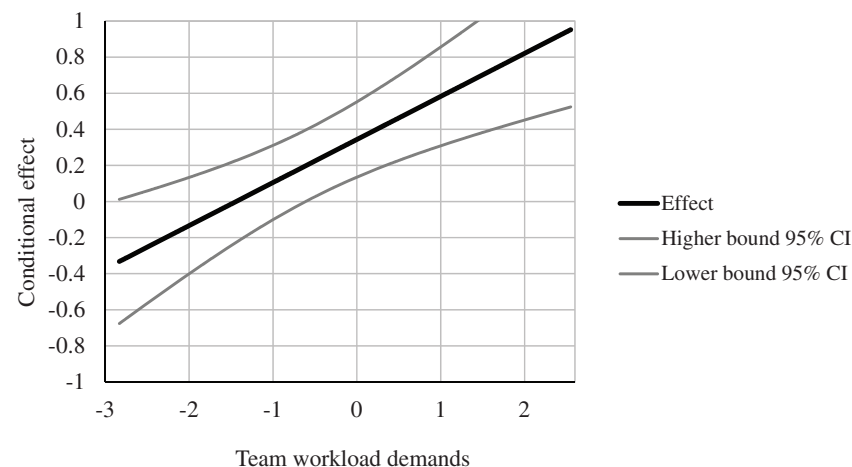

FIGURE 3 Johnson-Neyman plot of the interaction between boundary spanning and team vigor (Study 1). Standardized effects and standardized values of team workload demands

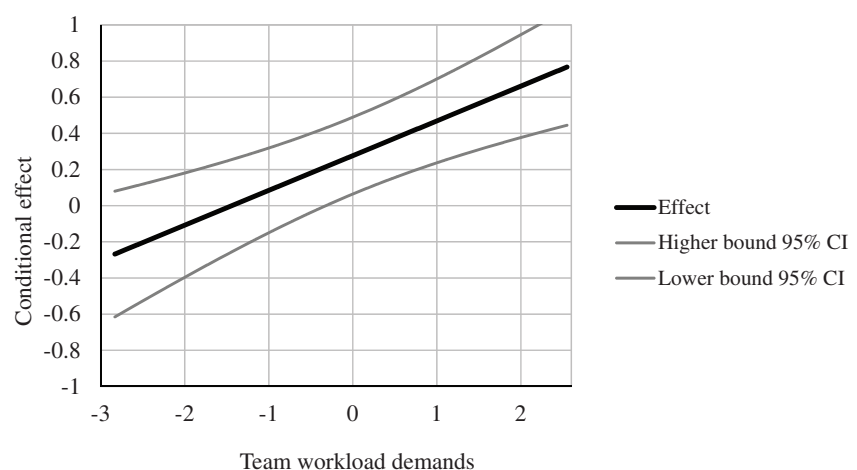

FIG URE 5 Johnson-Neyman plot of the interaction between boundary buffering and team vigor (Study 1). Standardized effects and standardized values of team workload demands 
TAB LE 3 Descriptive statistics and correlations (Study 2)

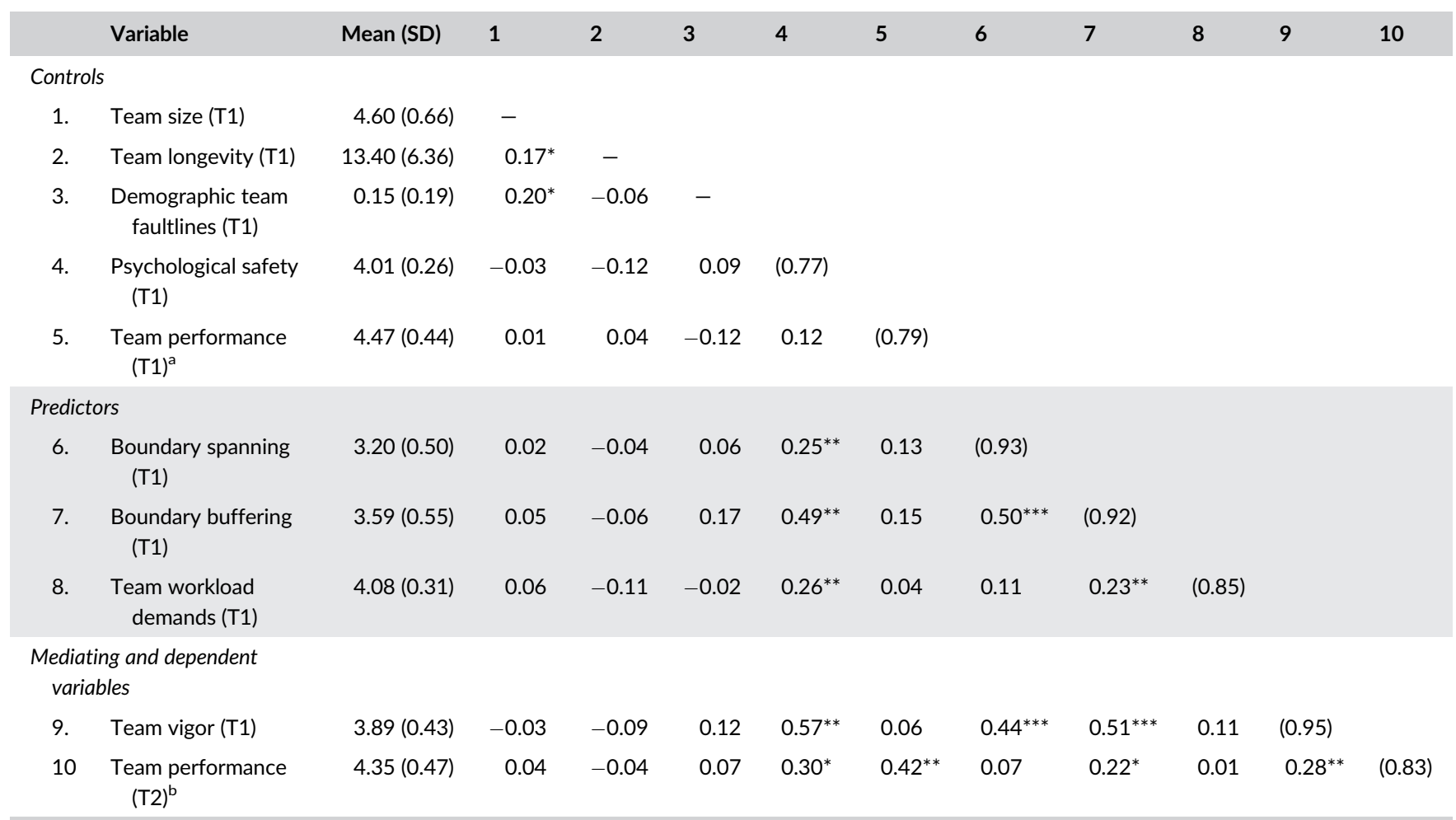

Note: $N=139$ teams. Cronbach's alphas appear in parentheses across the diagonal.

${ }^{a} \mathrm{n}=131$ teams.

${ }^{b} n=124$ teams.

${ }^{*} p<0.05 ;{ }^{* *} p<0.01 ;{ }^{* * *} p<0.001$ (two-tailed).

$\mathrm{H} 5 \mathrm{a}$ predicts that team workload demands moderate the mediated effect of boundary buffering on team innovation through team vigor, such that the positive indirect effect is stronger when team workload demands are higher. When team workload demands were high ( $+1 \mathrm{SD}$ ), the indirect effect through team vigor was positive and significant (high: $a \times b=0.11$ [0.01, 0.24]). In contrast, when team workload demands were low ( $-1 \mathrm{SD})$, boundary buffering was unrelated to team innovation through team vigor (low: $a \times b=0.03$, $\mathrm{Cl}[-0.05,0.12])$. Thus, $\mathrm{H} 5 \mathrm{a}$ is supported.

\section{6 | Study 1: Discussion}

The findings of Study 1 suggest that both boundary spanning and boundary buffering are positively associated with team vigor, which in turn is associated with higher levels of team innovation. Furthermore, the results suggest that the positive association between team boundary work and team innovation via team vigor is moderated by team workload demands, such that the mediated association is stronger when team workload demands are higher.

Study 1 has several strengths and weaknesses. A key strength is that it examines the hypotheses with a large sample of R\&D teams involved in frequent interactions with their external environment, providing ample opportunities to examine team boundary work. Furthermore, our research design avoids common-source bias between data sources (P. M. Podsakoff et al., 2003). However, the study also has some weaknesses. First, we tested team innovation as an outcome, but we did not consider team performance. Second, the study's crosssectional nature raises concerns of reverse causality. Third, team vigor was evaluated by team leaders and not by individual team members, which gives rise to the possibility that team leaders' ratings of team vigor might reflect team leaders' observations of team vigor rather than team members' actual experiences of it. We conducted a second study using a sample from a different culture and industry (i.e., a Chinese utility firm) to provide a constructive replication addressing these limitations (Köhler \& Cortina, 2019) and to test the remaining hypotheses regarding team performance $(\mathrm{H} 3 \mathrm{~b}, \mathrm{H} 4 \mathrm{~b}$, and $\mathrm{H} 5 \mathrm{~b})$.

\section{7 | Study 2: Methods}

\subsection{1 | Sample and procedure}

We collected data from teams across multiple units, such as human resources, accounting, and operations and manufacturing, in an electricity production and supply company in China. The majority of the team sample came from the Operation and Manufacturing Departments. Their team tasks included material procurement, material quality control, electricity safety, manufacturing system operation (i.e., fuel system, combustion system, steam water system, electrical 
system, and control system), production planning, personnel training, and environmental-influence control. The company's success depended heavily on multiple teams working together, thereby making boundary-spanning and boundary-buffering activities common across teams. To fulfill those tasks, teams frequently had to interact and collaborate with other teams, members of from top management, and parties outside the firm.

Prior to starting our data collection process, we held a meeting with participants to inform them that their responses would be kept confidential and that participation in the survey was voluntary.
Furthermore, the HR director sent an email to all participants describing the importance of the survey and the firms' privacyprotection policies. We undertook two waves of data collection with a time lag of 1 month between them. We implemented this 1-month time lag for three reasons. First, drawing from Hackman's (1983) model of team effectiveness, we suggest that a time lag of several weeks is preferable for capturing tangible effects of current team vigor on later team performance. In this regard, this 1-month time interval is consistent with past research on team boundary work (Bailey, 2000; C. H. Chen et al., 2010). Second, most

TA B LE 4 Path model results for team vigor and team performance (Study 2)

\begin{tabular}{|c|c|c|c|c|c|c|c|c|}
\hline \multirow{2}{*}{$\begin{array}{l}\text { Predictor } \\
\text { Mediator variable: Team vigor }\end{array}$} & \multicolumn{2}{|c|}{$\begin{array}{l}\text { Model } 5 \\
\text { Mediation-only } \\
\beta\end{array}$} & \multicolumn{2}{|c|}{$\begin{array}{l}\text { Model } 6 \\
\text { Moderated mediation } \\
\beta\end{array}$} & \multicolumn{2}{|c|}{$\begin{array}{l}\text { Model } 7 \\
\text { Moderated mediation } \\
\beta\end{array}$} & \multicolumn{2}{|c|}{$\begin{array}{l}\text { Model } 8 \\
\text { Moderated mediation } \\
\beta\end{array}$} \\
\hline & & & & & & & & \\
\hline \multicolumn{9}{|l|}{ Controls } \\
\hline Team size & 0.01 & $(0.07,0.888)$ & 0.03 & $(0.07,0.661)$ & 0.02 & $(0.07,0.750)$ & 0.03 & $(0.07,0.646)$ \\
\hline Team longevity & -0.04 & $(0.07,0.511)$ & -0.06 & $(0.06,0.353)$ & -0.05 & $(0.06,0.468)$ & -0.06 & $(0.06,0.366)$ \\
\hline Team psychological safety & $0.48^{* * *}$ & $(0.07,0.000)$ & $0.45^{* * *}$ & $(0.07,0.000)$ & $0.48^{* * *}$ & $(0.07,0.000)$ & & \\
\hline \multicolumn{9}{|l|}{ Predictors } \\
\hline Boundary spanning (H1a) & $0.25^{* * *}$ & $(0.07,0.000)$ & $0.25^{* * *}$ & $(0.07,0.000)$ & $0.27^{* * *}$ & $(0.07,0.000)$ & $0.26^{* * *}$ & $(0.07,0.000)$ \\
\hline Boundary buffering ( $\mathrm{H} 1 \mathrm{~b})$ & $0.16^{*}$ & $(0.08,0.043)$ & $0.20^{*}$ & $(0.08,0.016)$ & $0.16^{*}$ & $(0.08,0.042)$ & $0.19^{* * *}$ & $(0.08,0.021)$ \\
\hline $\begin{array}{l}\text { Boundary buffering } \times \text { team job } \\
\text { demands }(\mathrm{H} 2 \mathrm{~b})\end{array}$ & & & & & $0.11^{\dagger}$ & $(0.06,0.086)$ & 0.05 & $(0.08,0.500)$ \\
\hline$R^{2}$ & 0.48 & & 0.50 & & 0.50 & & 0.50 & \\
\hline$\Delta R^{2}$ interaction term & & & $0.02^{*}$ & & $0.02^{\dagger}$ & & $0.01^{\dagger}$ & \\
\hline \multicolumn{9}{|c|}{ Dependent variable: Team performance } \\
\hline \multicolumn{9}{|l|}{ Controls } \\
\hline Team performance (T1) & $0.42^{* * *}$ & $(0.07,0.000)$ & $0.42^{* * *}$ & $(0.07,0.000)$ & $0.42^{* * *}$ & $(0.07,0.000)$ & $0.42^{* * *}$ & $(0.07,0.000)$ \\
\hline Team size & 0.00 & $(0.08,0.996)$ & -0.02 & $(0.08,851)$ & 0.00 & $(0.08,0.983)$ & -0.01 & $(0.08,0.866)$ \\
\hline Team longevity & 0.02 & $(0.08,0.796)$ & 0.03 & $(0.08,0.668)$ & 0.02 & $(0.08,0.780)$ & 0.04 & $(0.08,0.660)$ \\
\hline $\begin{array}{l}\text { Boundary buffering } \times \text { team job } \\
\text { demands }\end{array}$ & & & & & -0.04 & $(0.08,0.617)$ & 0.04 & $(0.10,0.689)$ \\
\hline \multicolumn{9}{|l|}{ Predictor } \\
\hline Team vigor $(\mathrm{H} 3 \mathrm{~b})$ & $0.25^{*}$ & $(0.11,0.019)$ & $0.28^{*}$ & $(0.11,0.010)$ & $0.25^{* *}$ & $(0.11,0.017)$ & $0.28^{*}$ & $(0.11,0.010)$ \\
\hline$R^{2}$ & 0.30 & & 0.31 & & 0.30 & & 0.31 & \\
\hline
\end{tabular}

Note: Standardized path coefficients are reported. Values in parentheses are the standard errors and the exact $p$ values.

${ }^{\dagger} p<0.10,{ }^{*} p<0.05,{ }^{* *} p<0.01,{ }^{* * *} p<0.001$ (two-tailed). 
of the teams in the focal operation and manufacturing departments had project cycles of several weeks. Therefore, a 1-month timeframe allowed us to capture at least one project cycle. Finally, the participating organization was unwilling to conduct two surveys within a short period of time (e.g., 2 weeks) due to the potential for work interference and survey fatigue.

Participants filled in paper-and-pencil-based questionnaires. To match individual responses at Time 1 and Time 2, participants were assigned a unique identifier. After completing the questionnaires, participants returned their responses directly to a member of the research team in a sealed envelope. Participants who completed both questionnaires received approximately USD 6 as a token of our appreciation.

We collected data from two data sources to reduce common method bias (P. M. Podsakoff et al., 2003). Data on boundary spanning (Time 1), boundary buffering (Time 1), team workload demands (Time 1), and team vigor (Time 1) was collected from team members, while data on team performance (Time 1 and Time 2) was collected from team leaders.

We distributed surveys to 784 team members and 139 team leaders. Our final sample comprised 139 teams (724 team members at Time 1; 113 team leaders at Time 1; and 107 team leaders at Time 2 ), representing response rates of $92 \%$ for team members, $81 \%$ for team leaders at Time 1 , and $77 \%$ for team leaders at Time 2 . The mean intrateam response rate was $85 \%$. The majority of team members were male (55\%) and held a university degree (74\%). The average team member was 43 years old $(S D=5.27)$ and had worked for the company for 21.16 years ( $S D=6.43$ years). All participants' first language was Chinese.

\subsection{2 | Measures}

Study 2 included the same measures as Study 1 except that our dependent variable was team performance instead of team innovation in order to test $\mathrm{H} 3 \mathrm{~b}, \mathrm{H} 4 \mathrm{~b}$, and $\mathrm{H} 5 \mathrm{~b}$. All materials were presented in Chinese. Two independent bilingual researchers translated the items from English into Chinese and then translated them back into English (Brislin, 1986).

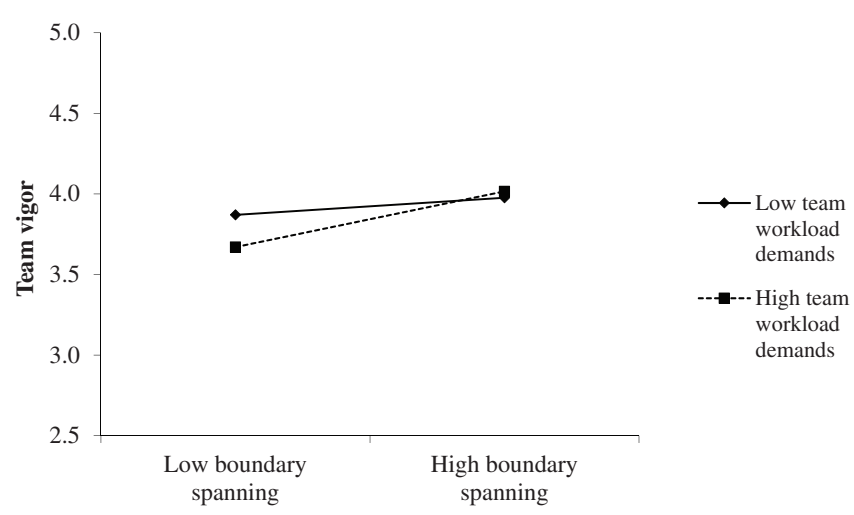

FIGURE 6 Moderating effect of team workload demands on the relationship between boundary spanning and team vigor (Study 2)

\section{Team performance}

We evaluated team performance using a measure developed by Ancona and Caldwell (1992), which is based on team performance dimensions suggested by Hauptman (1986). Team leaders rated their teams': (1) efficiency, (2) adherence to schedules, (3) adherence to budgets, (4) ability to resolve conflicts, (5) overall productivity, and (6) number of employees that had called sick over the past year using a Likert-type scale ranging from (1) "strongly disagree" to (5) "strongly agree."

\section{Controls}

In our analyses, we controlled for the same variables as in Study 1. In addition, we controlled for team performance at Time 1 when we modeled team performance as the dependent variable at Time 2 to examine whether Time 1 team vigor predicted the change in team performance from Time 1 to Time 2 . Our results hold without the inclusion of these controls (see Table A3).

\subsection{3 | Analytical strategy}

\section{Aggregation statistics}

As in Study 1, to justify the aggregation of our focal variables to the team level, we computed $r_{\text {wg }}$ and ICC values. Boundary spanning had a median $r_{\text {wg }}$ value of 0.68 , which is slightly lower than the generally accepted value of 0.70 . The ICC [1,2] values were 0.08 and 0.23 . Boundary buffering had a median $r_{w g}$ value of 0.76 with ICC [1,2] values of 0.22 and 0.56 , respectively. Team workload demands had a median $r_{\mathrm{wg}}$ value of 0.88 with ICC [1,2] values of 0.04 and 0.16 , respectively. Team vigor had a median $r_{w g}$ value of 0.78 with ICC $[1,2]$ values of 0.12 and 0.31 , respectively. In sum, these values provide adequate support for aggregation to the team level (James et al., 1984).

\section{Path modeling}

We applied a path model with full-maximum likelihood estimation to account for the missing data in team performance (time 1: $n=131$, time 2: $n=124$ ) (Enders \& Bandalos, 2001).

Prior to the analysis, we tested the discriminant validity of our six main study variables (i.e., boundary spanning, boundary buffering, team

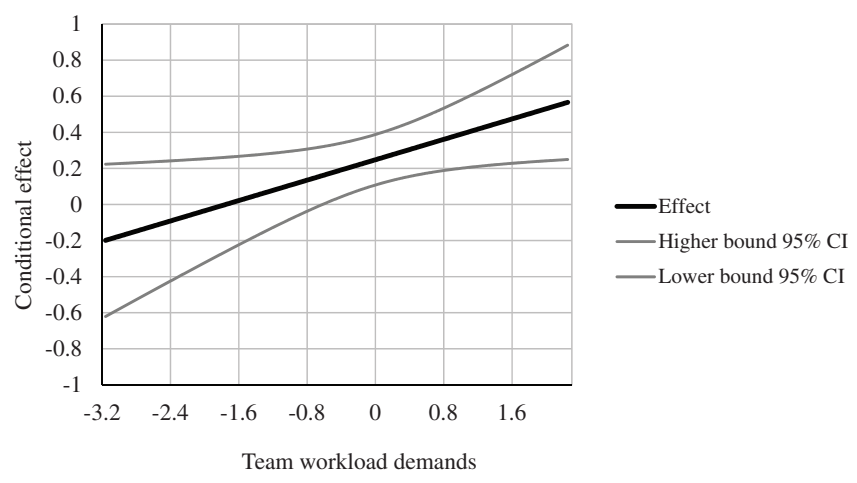

FIG URE 7 Johnson-Neyman plot of the interaction between boundary spanning and team vigor (Study 2). Standardized effects and standardized values of team workload demands 
workload demands, team vigor, and team performance [Times 1 and 2]) with CFAs. A six-factor measurement model showed a good fit to the data $\chi^{2}[390]=521.44, p<0.001 ; \mathrm{CFI}=0.95 ; \mathrm{TL}=0.94 ;$ RMSEA $=0.04 ;$ SRMR $=0.06$; see Table $A 4$ ), suggesting that our six variables are empirically distinct. All standardized factor loadings were significant and above 0.40 .

We centered the independent variables on the mean prior to analysis to reduce potential problems of multicollinearity (Aiken \& West, 1991). All VIF values were less than 1.6, which is below the cutoff of 10 , indicating that multicollinearity was not a serious problem in our analysis (Aiken \& West, 1991). Similar to Study 1 , we first specified a structural equation model without the interaction term to test the main effects. This model showed a good fit to the data (Table 4, Model 5: $\chi^{2}[1]=0.73$, $p=0.392 ; \mathrm{CFI}=1.00, \mathrm{TLI}=1.00, \mathrm{RMSEA}=0.00, \mathrm{SRMR}=0.02$ ). In the next step, we added the interaction terms in order to inspect the incremental explained variance of the moderations. These moderated mediation models exhibited a good fit to the data (Model 6: $\chi^{2}[1]=0.62, p=0.430, \mathrm{CFI}=1.00, \mathrm{TLI}=1.00$, RMSEA $=0.00$, SRMR $=0.02 ;$ Model 7: $\chi^{2}[1]=0.45$, $p=0.502, \mathrm{CFI}=1.00, \mathrm{TLI}=1.00, \mathrm{RMSEA}=0.00, \mathrm{SRMR}=0.01$; Model 8: $\chi^{2}[1]=0.42, p=0.472, \mathrm{CFI}=1.00, \mathrm{TLI}=1.00$, RMSEA $=0.00$, SRMR $=0.01$.

\section{Conditional indirect effects}

To test the conditional indirect effects specified in $\mathrm{H} 4 \mathrm{~b}$ and $\mathrm{H} 5 \mathrm{~b}$, we computed $95 \%$ bias-corrected Cls with 1000 bootstrapping resamples of these indirect effects (MacKinnon et al., 2004).

\section{8 | Study 2: Results}

\subsection{1 | Research model}

Table 3 shows the descriptive statistics, correlations, and alpha coefficients of each variable. We tested $\mathrm{H} 1 \mathrm{a}$ and $\mathrm{H} 1 \mathrm{~b}$ with a mediation-only model. $\mathrm{H} 1 \mathrm{a}$ and $\mathrm{H} 1 \mathrm{~b}$ predict that boundary spanning and boundary

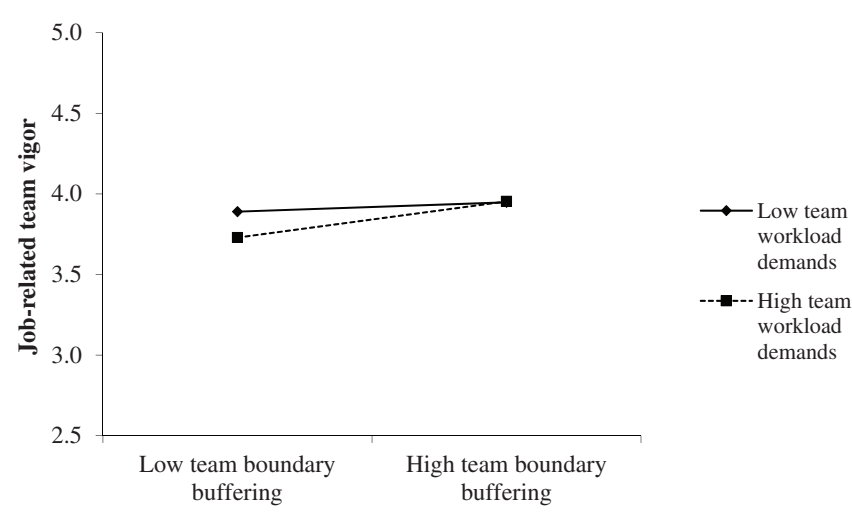

FIGURE 8 Moderating effect of team workload demands on the relationship between boundary buffering and team vigor (Study 2) buffering are positively associated with team vigor, respectively. As shown in Table 4 (Model 5), the coefficients of boundary spanning $(\beta=0.25, \mathrm{SE}=0.07, p<0.001)$ and boundary buffering $(\beta=0.16$, $\mathrm{SE}=0.08, p=0.043$ ) were positive and significant. Hence, $\mathrm{H} 1 \mathrm{a}$ and $\mathrm{H} 1 \mathrm{~b}$ are supported.

$\mathrm{H} 2 \mathrm{a}$ predicts that team workload demands moderate the relationship between boundary spanning and team vigor, such that the positive relationship is stronger when team workload demands are higher. As shown in Table 4 (Model 6), the coefficient for the interaction between boundary spanning and team workload demands was positive and significant $(\beta=0.14, \mathrm{SE}=0.08, p=0.033$ ). Figure 6 shows the moderating effect of team workload demands on the association between boundary spanning and team vigor. Simple slope analyses revealed that the slope was positive and significant $(\beta=0.39$, $\mathrm{SE}=0.09, p<0.001)$ at high levels of team workload demands $(+1$ $\mathrm{SD})$, whereas it was not significant $(\beta=0.12, \mathrm{SE}=0.10, p=0.207)$ at low levels of team workload demands ( -1 SD). When compared to the mediation-only model, the explained variance of team vigor significantly increased by $2 \%$ in the moderated mediation model (Table 4 , Model 5: $\Delta R^{2}=0.02 ; p=0.035$ ).

In addition, we calculated exact regions of significance for the interaction between boundary spanning and team workload demands using 95\% bias-corrected $\mathrm{Cls}$ and plotted the interaction using a Johnson-Neyman plot (see Figure 7). We found that boundary spanning had a positive and significant relationship with team vigor when the standardized values of team workload demands were -0.62 or higher (the $\beta$ at this transition point was $0.16, \mathrm{Cl}[0.0001,0.32]$ ). The strength of the positive association between boundary spanning and team vigor increased to a $\beta$ of $0.56(\mathrm{Cl}[0.25,0.88])$ when team workload demands reached the maximum standardized sample value of 2.25. Furthermore, when the standardized values of team workload demands were below -0.62 , boundary spanning had no significant relationship with team vigor. As such, the link between boundary spanning and team vigor was positive and significant for 100 teams (72\%), not significant for 39 teams (28\%).

$\mathrm{H} 2 \mathrm{~b}$ predicts that team workload demands moderate the relationship between boundary buffering and team vigor, such that the

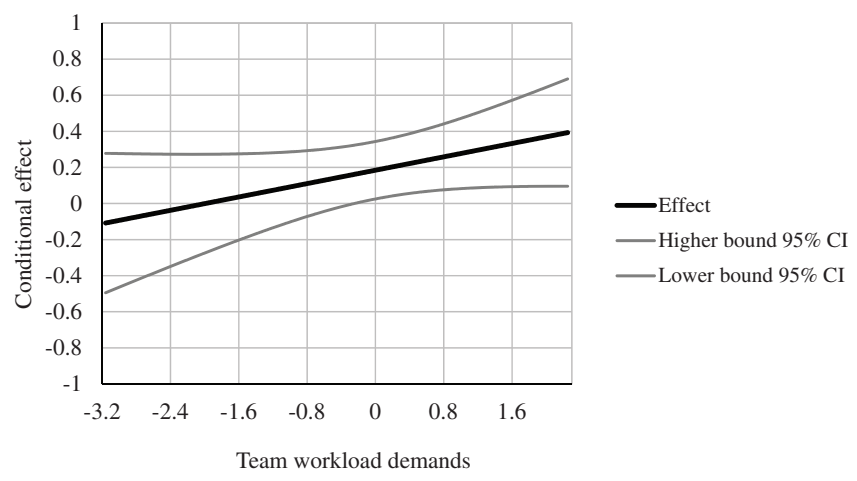

FIGURE 9 Johnson-Neyman plot of the interaction between boundary buffering and team vigor (Study 2). Standardized effects and standardized values of team workload demands 
TABLE 5 Indirect effects (Studies 1 and 2)

\begin{tabular}{|c|c|c|c|c|c|}
\hline Independent variable & Mediator & Moderator value & dEffect $_{\text {Boot }}$ & \multicolumn{2}{|l|}{ 95\%-BootCl } \\
\hline Study 1 & Team vigor & Team workload demands & & & \\
\hline \multirow[t]{3}{*}{ Boundary spanning } & & $+1 \mathrm{SD}$ & $0.23^{*}$ & 0.05 & 0.51 \\
\hline & & M & $0.11^{*}$ & 0.01 & 0.26 \\
\hline & & $-1 \mathrm{SD}$ & 0.05 & -0.05 & 0.17 \\
\hline \multirow{2}{*}{ Boundary buffering } & & M & $0.07^{*}$ & 0.003 & 0.17 \\
\hline & & $-1 \mathrm{SD}$ & 0.03 & -0.05 & 0.12 \\
\hline Study 2 & & Team workload demands & & & \\
\hline Boundary spanning & Team vigor & $+1 \mathrm{SD}$ & $0.10^{*}$ & 0.02 & 0.24 \\
\hline \multirow{2}{*}{ Boundary buffering } & & M & 0.04 & 0.000 & 0.12 \\
\hline & & $-1 \mathrm{SD}$ & 0.01 & -0.05 & 0.09 \\
\hline
\end{tabular}

Note: Bias-corrected confidence intervals (Cls) with 1000 bootstrapping resamples. Controlling for team size, team longevity, demographic team faultlines, and prior performance (T1).

${ }^{*} p<0.05$ (two-tailed).

positive relationship is stronger when team workload demands are higher. As shown in Table 4 (Model 7), the coefficient for the interaction between boundary buffering and team workload demands was positive and marginally significant $(\beta=0.11, \mathrm{SE}=0.06, p=0.086$ ). Figure 8 shows the moderating effect of team workload demands on the association between boundary buffering and team vigor. Simple slope analyses revealed that the slope was positive and significant $(\beta=0.26$, SE $=0.10, p<0.008)$ at high levels of team workload demands ( $+1 \mathrm{SD})$, while it was not significant $(\beta=0.07, \mathrm{SE}=0.10$, $p=0.499$ ) at low levels of team workload demands ( $-1 \mathrm{SD})$. When compared to the mediation-only model, the explained variance of team vigor marginally significantly increased by $1 \%$ in the moderated mediation model (Table 4, Model 7: $\Delta R^{2}=0.01, p<0.081$ ).

In addition, we calculated exact regions of significance for the interactions between boundary buffering and team workload demands using $95 \%$ bias-corrected $\mathrm{Cls}$ and plotted the interaction using a Johnson-Neyman plot (see Figure 9). We found that boundary buffering had a positive and significant relationship with team vigor when the standardized values of team workload demands were -0.24 or higher (the $\beta$ at this transition point was $0.16, \mathrm{Cl}[0.001,0.32]$ ). The strength of the positive association increased to a $\beta$ of $0.39(\mathrm{Cl}[0.10$, 0.69]) when team workload demands reached the maximum standardized sample value of 2.25. Moreover, when the standardized values of team workload demands were below -0.24 , team workload demands had no significant relationship with team vigor. As such, the link between boundary spanning and team vigor was positive and significant for 78 teams (56\%) and not significant for 61 teams (44\%) in our sample. These findings provide qualified support for $\mathrm{H} 2 \mathrm{~b}$.

$\mathrm{H} 3 \mathrm{~b}$ predicts that team vigor is positively associated with team performance. As shown in Table 4 (Model 5), the effect of team vigor on team performance was positive and significant $\beta=0.25$, $\mathrm{SE}=0.11, p=0.019)$. Thus, $\mathrm{H} 3 \mathrm{~b}$ is supported.

$\mathrm{H} 4 \mathrm{~b}$ predicts that team workload demands moderate the mediated effect of boundary spanning on team performance through team vigor, such that the positive indirect effect is stronger when team workload demands are higher. As shown in Table 5, when team workload demands were high ( $+1 \mathrm{SD}$ ), the indirect effect through team vigor was positive and significant (high: $a \times b=0.10, \mathrm{Cl}[0.02,0.24]$ ). In contrast, when team workload demands were low ( $-1 \mathrm{SD})$, boundary spanning was unrelated to team performance through team vigor (low: $a \times b=0.03 \mathrm{Cl}[-0.02,0.14]$ ). Thus, $\mathrm{H} 4 \mathrm{~b}$ is supported.

$\mathrm{H} 5 \mathrm{~b}$ predicts that team workload demands moderate the mediated effect of boundary buffering on team performance through team vigor, such that the positive indirect effect is stronger when team workload demands are higher. As shown in Table 5, when levels of team workload demands were high ( $+1 \mathrm{SD})$, the indirect effect through team vigor was positive and significant (high: $a \times b=0.06$ $[0.002,0.15])$. In contrast, when levels of team workload demands were low ( $-1 \mathrm{SD})$, boundary buffering was unrelated to team performance through team vigor (low: $a \times b=0.01, \mathrm{Cl}[-0.05,0.09]$ ). Thus, $\mathrm{H} 5 \mathrm{~b}$ is supported.

\subsection{Study 2: Discussion}

Study 2 builds on the findings of Study 1 in four ways. First, we extended the generalizability of our model to predicting team performance. Second, we followed best-practice recommendations to address concerns regarding reverse causality by measuring our independent variables and dependent variable at two points in time and 
controlling for team performance at Time 1 when predicting team performance in Time 2 (Maxwell \& Cole, 2007; Ployhart \& Vandenberg, 2010). Third, we constructively replicated Study 1 's findings that boundary work is positively associated with team vigor, which, in turn, is positively associated with team innovation. We further largely replicated the finding that the positive mediated effect is altered by team workload demands, such that the effect of boundary work on team performance is stronger when team workload demands are higher. Finally, we tested and found empirical support for our theoretical model in a Chinese context, which enhances the generalizability of our theory to a different setting.

\section{3 | GENERAL DISCUSSION}

Consistent with team-level JD-R theory, we found in both studies that team boundary work (i.e., boundary spanning and boundary buffering) is positively related to team vigor, which is positively related to team innovation (Study 1) and team performance (Study 2). Furthermore, in both studies, the positive indirect relationship between boundary spanning and team effectiveness via team vigor is moderated by team workload demands, such that the mediated relationship is stronger when team workload demands are higher.

\section{1 | Theoretical implications}

Our work contributes to the boundary work literature in two ways. First, drawing from JD-R theory, our work sheds light on when team boundary work matters for team effectiveness. Although team scholars have begun to examine the contingencies of team boundary work (Faraj \& Yan, 2009; Gibson \& Dibble, 2013; Sleep et al., 2015), "surprisingly little empirical attention has been paid thus far to possible moderating conditions of the team boundary spanning-team performance relationship" (Marrone, 2010, p. 927). In extending the current literature, our study identifies a theorydriven boundary condition-team workload demands-that strengthens the positive effect of team boundary work and team effectiveness via team vigor. Furthermore, we demonstrate that team boundary work is effective when teams face substantial team workload demands. As such, our work explains why some prior studies have found nonsignificant (Haas, 2006; Lewis et al., 2002; Sawyer et al., 2010) or even negative relationships (AtuaheneGima, 2003; Hansen, 1999; Katz, 1982), thereby providing a more complete understanding of when team boundary work matters for team effectiveness.

The marginally significant interaction between boundary buffering and team workload demands in Study 2 might suggest that boundary spanning and boundary buffering function somewhat differently. In our theory, we highlighted that boundary spanning aims to broaden the extent and breadth of novel job resources, while boundary buffering is directed at protecting the pool of job resources available to a team. The conservation of resources theory offers one reason for our finding of only a marginally significant interaction in Study 2-team members may assign a premium to avoiding resource losses rather than gaining new resources (Halbesleben et al., 2014). Hence, the need to buffer the existing team job resources might be more fundamental than acquiring additional resources. Future research should clarify these interesting differences in the roles and functions of boundary spanning and boundary buffering in acquiring and protecting team job resources.

Second, our studies are among the first to explicitly test and find empirical support for the relationship between team boundary work and team effectiveness by pointing to an affective motivational mechanism. As such, this research improves our understanding of how boundary work operates. Only by uncovering this mechanism could we also test team workload demands as a boundary condition for the relationship between boundary work and team effectiveness. As such, the unveiling of an affective motivational mechanism linking boundary work with team effectiveness is a crucial and necessary step in our accumulation of knowledge in the team boundary work literature, especially given that theoretical mechanisms are a necessary aspect of organizational theories, but are often absent from empirical research (Sutton \& Staw, 1995). Importantly, in this regard, we replicate Faraj and Yan's (2009) finding that team psychological safety does not explain the relationship between team boundary work and team effectiveness. By unveiling team vigor as an explanatory mechanism, our work not only helps future research redirect its energies toward testing other meditating mechanisms, but also motivates future scholars to examine the boundary conditions beyond team workload demands under which boundary work is more or less effective in promoting team effectiveness.

Finally, our work also has implications for JD-R theory. Most studies at the individual level tend to find that job resources and job demands have independent effects on job-related outcomes (i.e., an additive effect), while they do not interact to predict those outcomes (i.e., a multiplicative effect; Doef \& Maes, 1999; Gonzalez-Mulé et al., 2021). At the team level, we find support for a multiplicative effect, whereby team workload demands strengthen the associations among boundary work, team vigor, and team effectiveness. One reason why a multiplicative effect may be more likely at the team level might be that a team context allows members to help one other and, thereby, receive social support from one other, which should benefit their sense of control when confronted with high workload demands (Theorell \& Karasek, 1996). All in all, our research points to the possibility that a multiplicative effect between job demands and job resources may be more likely at the team level of analysis than at the individual level.

\section{2 | Practical implications}

Our findings provide insights into how organizations and teams can execute boundary work in a more effective manner. Leaders and members of teams may assume that, when faced with high team workload demands, they should engage in less boundary work in order 
to conserve their time and energy. However, our research highlights that it exactly under these circumstances that teams should perform boundary work because it can help teams acquire additional job resources. Jobs with such characteristics have been termed "active" jobs at the individual level of analysis (Theorell \& Karasek, 1996) because they are characterized by high demands as well as control and support. Furthermore, team workload demands provide organizations with an important lever through which team members can experience higher team vigor and team effectiveness. Notably, however, the organization must use this lever with caution and should ensure that teams have the leeway and ability to engage in boundary work, and provide training and agency for them to successfully execute such team boundary work.

\subsection{Limitations and future research}

Our contributions should be considered in the light of several limitations. First, although we have followed best-practice recommendations to mitigate concerns regarding reverse causality (Maxwell \& Cole, 2007; Ployhart \& Vandenberg, 2010), it is reasonable to assume that teams with higher levels of team vigor take on more workload demands and engage in more boundary work. Although our research design for Study 2 had a time lag of 1 month between the ratings of team vigor and team performance, we did not include time lags between team boundary work, team workload demands, and team vigor because we assume that the associations between boundary work and team vigor and between team workload demands and team vigor are fairly dynamic and fluctuate over relatively short periods of time (Demerouti et al., 2012). We encourage future research to measure boundary work, team workload demands, and team vigor at multiple points in time to further address possible reverse-causality issues present in our research.

A useful theoretical lens for studying the dynamic relationships among team boundary work, team workload demands, and team vigor over time may be the conservation of resources theory. This theory suggests that people starting off with more resources (i.e., high levels of team vigor) tend to be inclined to invest more of those resources (i.e., execute more boundary spanning and boundary buffering) than people starting off with fewer resources. As such, it would be interesting to investigate whether boundary work, team workload demands, and team vigor dynamically unfold over time through positive feedback loops or vicious circles (see Mäkikangas et al., 2010, and Xanthopoulou et al., 2009, for related work at the individual level of analysis). One way to capture the dynamic nature of boundary work, team workload demands, and team vigor would be to measure those three variables on a daily basis (Ohly et al., 2010) and apply growthcurve modeling (Collins et al., 2016). This would also allow for weak causal inferences to be drawn regarding the relationships among team boundary work, team workload demands, and team vigor (Antonakis et al., 2010).

Second, we conceptualize boundary spanning and boundary buffering as team processes that help the team acquire and protect job resources (Marks et al., 2001). This approach is consistent with JD-R research at the individual level that conceptualizes behavioral processes, such as social support from coworkers and supervisors (Breevaart et al., 2016) or acquiring information and knowledge (Bakker \& Demerouti, 2014), as representations of job resources. However, boundary spanning and boundary buffering do not directly tap team job resources or the nuances of how team members' use those resources (Feldman, 2004). As a robustness check, we conducted an empirical exploration using an ad hoc measure of team resources to better understand the role of team resources in our model. ${ }^{5}$ We gathered data on this measure in Study 2 (at Time 1). In this exploratory analysis, we found that boundary spanning and boundary buffering were indirectly associated with team performance through a serial mediation via (a) team resources and (b) team vigor (boundary spanning: $a \times b \times c=0.03,95 \% \mathrm{Cl}$ [0.01, 0.08]; boundary buffering: $a \times b \times c=0.02,95 \% \mathrm{Cl}[0.003,0.06])$. Future research might also use interpretative methods and resourcing theory (Feldman, 2004) to advance a finer-grained theory of how team members seek and interpret potential job resources in their team environment, and how they put those potential resources into use through team boundary work.

Third, one could argue that team boundary spanning and team boundary buffering need initial resource investments to be executed and, thus, are a type of team workload demands. However, other team processes, such as team coordination (Fleishman \& Zaccaro, 1992), planning (Prince \& Salas, 1993), monitoring (CannonBowers et al., 1995), and backing-up behavior (Barnes et al., 2008; Porter et al., 2010), also come with initial resource investments in terms of time and energy to be accomplished (Barnes et al., 2008; Porter et al., 2010) and have not been conceptualized as team workload demands. Although boundary work may come with initial costs, we suggest that its benefits outweigh these initial investments, which should typically result in a positive net utility of team boundary work (Marks et al., 2001; Porter et al., 2010). This argument is supported by an overall positive relationship between team boundary work and team performance in the prior literature (Dey \& Ganesh, 2017; Marrone, 2010). Future research may empirically examine the potential trade-off between costs (i.e., resource investments) and benefits (i.e., resource gains) of team boundary work and its possible moderating effect on the team boundary work-team performance relationship.

Fourth, in both studies, we focused on the most common types of team boundary work-boundary spanning and boundary buffering. However, prior research has also studied other types of boundary activities, such as boundary reinforcement (i.e., "the ways that a team internally sets and reclaims its team boundaries by increasing member awareness of boundaries and sharpening team identity;" Faraj \& Yan, 2009, p. 607). We did not include boundary reinforcement in our model because it does not match our conceptualization of team resources and, thus, cannot easily fit into the team-level JD-R framework. Instead, we expect boundary reinforcement to be explained by different mediating mechanisms, such as team identification or team cohesion (Richter et al., 2006). Future research might examine 
additional types of team boundary work, such as boundary reinforcement, and other mechanisms, such as team cohesion or team identification, that may influence team effectiveness. Furthermore, it might be useful to test potential confounds of the boundary work-team vigor relationship, such as a team's visibility within its focal organization.

Fifth, although we have tested and found support for an affective motivational mechanism of team vigor, other mechanisms might explain the link between team boundary work and team effectiveness. One opportunity for future research might be to examine the simultaneous effect of cognitive mechanisms, such as improved interteam coordination (Sleep et al., 2015) or team absorptive capacity (i.e., a team's ability to acquire new knowledge and information, and assimilate, transform, and exploit it; Backmann et al., 2015; Sung \& Choi, 2012), as mediating concepts above and beyond the role of the affective motivational mechanism of team vigor. Future research may explore whether a cognitive or affective mechanism is more predictive of team effectiveness, and whether both exert independent effects.

Finally, we note that the explained variance in team vigor is higher in Study 2 than in Study 1. One possible explanation is that Study 2 was conducted in China, where team members are often expected to take on additional responsibilities not formally included in their job descriptions. Moreover, in the Chinese setting, team members are often expected to establish guanxi with others to garner resources for themselves while maintaining their own resources to accomplish team tasks (Park \& Luo, 2001). Therefore, the combination of high team workload demands and boundary work may result in a stronger interactive association with team vigor and subsequent team effectiveness. We encourage future research that explores the role of boundary work and team workload demands across different national settings to better understand when boundary work is associated with higher levels of team vigor and subsequent team effectiveness.

\section{4 | CONCLUSION}

Across the two studies, we showed that both team boundary spanning and boundary buffering are positively related to team vigor, which, in turn, is positively associated with team effectiveness. We also demonstrated that the link between team boundary work and team effectiveness is more positive when team workload demands are high, but is unrelated when team workload demands are low. In extending the JD-R theory to the team level, our study represents one of the first attempts to understand when and how team boundary work matters for team effectiveness. We hope that our work encourages future research on team boundary work with the aim of uncovering potential mechanisms and boundary conditions responsible for the association between team boundary work and team effectiveness.

\section{ACKNOWLEDGMENTS}

The authors express thanks to HRM Associate Editor Brad Harris and the two anonymous reviewers for their thoughtful comments and the developmental review process as well as to Tina Petersen, Julia Denton, and Cynthia Lambert for their expert copy editing. We also thank Gretchen Spreitzer, Ryan Quinn, and John Hollenbeck for their constructive feedback on earlier versions of the manuscript. With gratitude, the authors acknowledge the feedback provided by participants at the INGroup conference, the EAWOP congress, and the Academy of Management Annual Meeting. A previous version of this paper has been included in the Academy of Management Annual Meeting's Best Paper Proceedings. This research was supported by the Basic Research Fund of the University of St. Gallen.

\section{DATA AVAILABILITY STATEMENT}

The data that support the findings of this study are available on request from the corresponding author. The data are not publicly available due to privacy or ethical restrictions.

\section{ORCID}

Ulrich Leicht-Deobald (DD https://orcid.org/0000-0003-4554-7192

\section{ENDNOTES}

1 Team vigor has important similarities to and differences from related concepts, such as team affect and team engagement. First, team vigor shares conceptual similarities with team affect. Following the circumplex model of affect (Russell, 1980), team vigor can be described as an affective team state of positive valence and high arousal, characterized by feelings of alertness, excitement, or elatedness (Barsade \& Gibson, 2007). However, team vigor differs from elements of team positive affect including both positive valence and low arousal, such as contentedness, sereneness, or relaxedness. Yet, vigor is similar to positive affect including positive valence and high arousal. Second, vigor shares some conceptual overlap with work engagement, as it is a subscale of the work-engagement concept (Schaufeli et al., 2006). However, in addition to vigor, work engagement encompasses the subdimensions of dedication (i.e., a state of "being strongly involved in one's work") or absorption (i.e., a state of "being fully concentrated"; (Schaufeli et al., 2006, p. 702). We focused on team vigor because it may manifest as a collective-level concept through emotional-contagion processes and interaction cycles (Barsade, 2002). In contrast, we found it more difficult to see how other subdimensions of work engagement, such as dedication or absorption, could manifest as a group-level phenomenon (Morgeson \& Hofmann, 1999).

2 Examples of job resources at the individual level of analysis include social support, skill utilization, and information important for accomplishing a task (Bakker et al., 2014; Schaufeli \& Bakker, 2004; Schaufeli \& Taris, 2014)

3 Based on Crawford et al.'s (2010) meta-analysis at the individual level of analysis, a positive association between (challenge) demands and vigor would be expected. However, as our primary interest was the role of team boundary work, we did not hypothesize this main effect.

${ }^{4}$ We found no significant differences between included and excluded teams in terms of team members' gender ( $F=1.13, p=0.291)$, age $(F=0.03, p=0.869)$, educational level $(F=0.03, p=0.866)$, team tenure $(F=0.36, p=0.551)$, or organizational tenure $(F=0.02, p=0.888)$. Therefore, we concluded that there was little indication of nonresponse bias in the data.

5 This ad hoc measure of team resources consisted of three items (alpha = 0.89): (1) "Members of this team have sufficient team resources available to fulfill their team tasks," (2) "Members of this team have the right team resources to help them execute their team tasks," and 
(3) "Members of this team use team resources such that they can perform their team tasks."

\section{REFERENCES}

Aiken, L. S., \& West, S. G. (1991). Multiple regression: Testing and interpreting interactions. Sage.

Ancona, D. G. (1990). Outward bound: Strategies for team survival in an organization. Academy of Management Journal, 33(2), 334-365. https://doi.org/10.2307/256328

Ancona, D. G., \& Caldwell, D. F. (1988). Beyond task and maintenance: Defining external functions in groups. Group \& Organization Studies, 13(4), 468-494. https://doi.org/10.1177/105960118801300405

Ancona, D. G., \& Caldwell, D. F. (1992). Bridging the boundary: External activity and performance in organizational teams. Administrative Science Quarterly, 37(4), 634-665. https://doi.org/10.2307/ 2393475

Antonakis, J., Bendahan, S., Jacquart, P., \& Lalive, R. (2010). On making causal claims: A review and recommendations. Leadership Quarterly, 21(6), 1086-1120. https://doi.org/10.1016/j.leaqua.2010.10.010

Asparouhov, T. (2006). General multi-level modeling with sampling weights. Communications in Statistics-Theory and Methods, 35(3), 439-460. https://doi.org/10.1080/03610920500476598

Asparouhov, T., \& Muthén, B. O. (2010). Resampling methods in Mplus for complex survey data. Structural Equation Modeling, 14(4), 535-569.

Atuahene-Gima, K. (2003). The effects of centrifugal and centripetal forces on product development speed and quality: How does problem solving matter? Academy of Management Journal, 46(3), 359-373. https://doi. org/10.5465/30040629

Atwater, L., \& Carmeli, A. (2009). Leader-member exchange, feelings of energy, and involvement in creative work. Leadership Quarterly, 20(3), 264-275. https://doi.org/10.1016/j.leaqua.2007.07.009

Backmann, J., Hoegl, M., \& Cordery, J. L. (2015). Soaking it up: Absorptive capacity in interorganizational new product development teams. Journal of Product Innovation Management, 32(6), 861-877. https://doi. org/10.1111/jpim.12295

Bagozzi, R. P., \& Edwards, J. R. (1998). A general approach for representing constructs in organizational research. Organizational Research Methods, 1(1), 45-87. https://doi.org/10.1177/109442819800100104

Bailey, D. (2000). Modeling work group effectiveness in high-technology manufacturing environments. IIE Transactions, 32, 361-368. https:// doi.org/10.1080/07408170008963913

Bakker, A. B., \& Demerouti, E. (2014). Job demands-resources theory. In C. Cooper \& P. Chen (Eds.), Wellbeing: A complete reference guide (pp. $37-$ 64). Wiley-Blackwell. https://doi.org/10.1002/9781118539415. wbwell019

Bakker, A. B., Demerouti, E., \& Sanz-Vergel, A. I. (2014). Burnout and work engagement: The JD-R approach. Annual Review of Organizational Psychology and Organizational Behavior, 1, 389-411. https://doi.org/10. 1146/annurev-orgpsych-031413-091235

Bakker, A. B., Demerouti, E., Taris, T. W., \& Schreurs, P. J. G. (2003). A multigroup analysis of the job demands-resources model in four home care organizations. International Journal of Stress Management, 10(1), 16-38. https://doi.org/10.1037/1072-5245.10.1.16

Bakker, A. B., van Veldhoven, M., \& Xanthopoulou, D. (2010). Beyond the demand-control model: Thriving on high job demands and resources. Journal of Personnel Psychology, 9(1), 3-16. https://doi.org/10.1027/ 1866-5888/a000006

Barnes, C. M., Hollenbeck, J. R., Wagner, D. T., DeRue, D. S., Nahrgang, J. D., \& Schwind, K. M. (2008). Harmful help: The costs of backing-up behavior in teams. Journal of Applied Psychology, 93(3), 529-539. https://doi.org/10.1037/0021-9010.93.3.529

Barsade, S. G. (2002). The ripple effect: Emotional contagion and its influence on group behavior. Administrative Science Quarterly, 47(4), 644-675. https://doi.org/10.2307/3094912
Barsade, S. G., \& Gibson, D. E. (2007). Why does affect matter in organizations? Academy of Management Perspectives, 21(1), 36-59. https://doi. org/10.5465/AMP.2007.24286163

Barsade, S. G., \& Knight, A. P. (2015). Group affect. Annual Review of Organizational Psychology and Organizational Behavior, 2(1), 21-46. https:// doi.org/10.1146/annurev-orgpsych-032414-111316

Barsade, S. G., \& O'Neill, O. A. (2014). What's love got to do with it? A longitudinal study of the culture of companionate love and employee and client outcomes in a long-term care setting. Administrative Science Quarterly, 59(4), 551-598. https://doi.org/10.1177/ 0001839214538636

Becker, T. E. (2005). Potential problems in the statistical control of variables in organizational research: A qualitative analysis with recommendations. Organizational Research Methods, 8(3), 274-289. https://doi. org/10.1177/1094428105278021

Beehr, T. A., Walsh, J. T., \& Taber, T. D. (1976). Relationships of stress to individually and organizationally valued states: Higher order needs as a moderator. Journal of Applied Psychology, 61(1), 41-47. https://doi. org/10.1037/0021-9010.61.1.41

Breevaart, K., Bakker, A. B., Demerouti, E., \& Derks, D. (2016). Who takes the lead? A multi-source diary study on leadership, work engagement, and job performance. Journal of Organizational Behavior, 37(3), 309325. https://doi.org/10.1002/job.2041

Bresman, H. (2010). External learning activities and team performance: A multimethod field study. Organization Science, 21(1), 81-96. https:// doi.org/10.1287/orsc.1080.0413

Brislin, R. W. (1986). The wording and translation of research instruments. In W. J. Lonner, J. W. Berry, W. J. Lonner, \& J. W. Berry (Eds.), Field methods in cross-cultural research (pp. 137-164). Sage.

Cannon-Bowers, I. A., Tannenbaum, S. I., Salas, E., \& Volpe, C. E. (1995). Defining competencies and establishing team training requirements. In R. A. Guzzo, E. Salas, \& I. L. Goldstein (Eds.), Team effectiveness and decision making in organizations (pp. 333-380). Jossey-Bass.

Chen, C. H., Chang, Y. Y., \& Lin, M. J. (2010). The performance impact of post-M\&A interdepartmental integration: An empirical analysis. Industrial Marketing Management, 39(7), 1150-1161. https://doi.org/10. 1016/j.indmarman.2009.12.002

Chen, Y., Wang, H., \& Lee, C. (2009). Unlocking the effects of group faultlines on team innovation: The mediating role of team task conflict and collective efficacy. Paper presented at the meeting of the Sixtyeight Annual Meeting of the Academy of Management.

Chi, N. W., Chung, Y. Y., \& Tsai, W. C. (2011). How do happy leaders enhance team success? The mediating roles of transformational leadership, group affective tone, and team processes. Journal of Applied Social Psychology, 41(6), 1421-1454. https://doi.org/10.1111/j.15591816.2011.00767.x

Choi, J. N. (2002). External activities and team effectiveness: Review and theoretical development. Small Group Research, 33(2), 181-208. https://doi.org/10.1177/104649640203300202

Christian, M. S., Eisenkraft, N., \& Kapadia, C. (2015). Dynamic associations between somatic complaints, human energy, and discretionary behaviors: Experiences with pain fluctuations at work. Administrative Science Quarterly, 60(1), 66-102. https://doi.org/10.1177/0001839214553655

Collins, C. G., Gibson, C. B., Quigley, N. R., \& Parker, S. K. (2016). Unpacking team dynamics with growth modeling: An approach to test, refine, and integrate theory. Organizational Psychology Review, 6(1), 63-91. https://doi.org/10.1177/2041386614561249

Crawford, E. R., LePine, J. A., \& Rich, B. L. (2010). Linking job demands and resources to employee engagement and burnout: $A$ theoretical extension and meta-analytic test. Journal of Applied Psychology, 95(5), 834848. https://doi.org/10.1037/a0019364

Cross, R., Yan, A. M., \& Louis, M. R. (2000). Boundary activities in "boundaryless" organizations: A case study of a transformation to a teambased structure. Human Relations, 53(6), 841-868. https://doi.org/10. 1177/0018726700536004 
Cummings, J. N. (2004). Work groups, structural diversity, and knowledge sharing in a global organization. Management Science, 50(3), 352-364. https://doi.org/10.1287/mnsc.1030.0134

de Vries, T. A., Walter, F., Van der Vegt, G. S., \& Essens, P. J. M. D. (2014). Antecedents of individuals' interteam coordination: Broad functional experiences as mixed blessing. Academy of Management Journal, 57(5), 1334-1359. https://doi.org/10.5465/amj.2012.0360

DeChurch, L. A., \& Marks, M. A. (2006). Leadership in multiteam systems. Journal of Applied Psychology, 91(2), 311-329. https://doi.org/10. 1037/0021-9010.91.2.311

Demerouti, E., Bakker, A. B., Nachreiner, F., \& Schaufeli, W. B. (2001). The job demands-resources model of burnout. Journal of Applied Psychology, 86(3), 499-512. https://doi.org/10.1037/0021-9010.86.3.499

Demerouti, E., Bakker, A. B., Sonnentag, S., \& Fullagar, C. J. (2012). Workrelated flow and energy at work and at home: A study on the role of daily recovery. Journal of Organizational Behavior, 33(2), 276-295. https://doi.org/10.1002/job.760

Devine, D. J., \& Philips, J. L. (2001). Do smarter teams do better a metaanalysis of cognitive ability and team performance. Small Group Research, 32, 507-532. https://doi.org/10.1177/1046496401032 00501

Dey, C., \& Ganesh, M. P. (2017). Team boundary activity: A review and directions for future research. Team Performance Management, 23(56), 273-292. https://doi.org/10.1108/TPM-06-2016-0029

Doef, M. V., \& Maes, S. (1999). The job demand-Control (support) model and psychological well-being: A review of 20 years of empirical research. Work and Stress, 13(2), 87-114. https://doi.org/10.1080/ 026783799296084

Edmondson, A. C. (1999). Psychological safety and learning behavior in work teams. Administrative Science Quarterly, 44(2), 350-383. https:// doi.org/10.2307/2666999

Edmondson, A. C. (2003). Speaking up in the operating room: How team leaders promote learning in interdisciplinary action teams. Journal of Management Studies, 40(6), 1419-1452. https://doi.org/10.1111/ 1467-6486.00386

Ellis, A. P. J., \& Pearsall, M. J. (2011). Reducing the negative effects of stress in teams through cross-training: Job demands-resources model. Group Dynamics, 15(1), 16-31. https://doi.org/10.1037/a0021070

Enders, C. K., \& Bandalos, D. L. (2001). The relative performance of full information maximum likelihood estimation for missing data in structural equation models. Structural Equation Modeling, 8(3), 430-457. https://doi.org/10.1207/S15328007SEM0803_5

Faraj, S., \& Yan, A. M. (2009). Boundary work in knowledge teams. Journal of Applied Psychology, 94(3), 604-617. https://doi.org/10.1037/ a0014367

Feldman, M. S. (2004). Resources in emerging structures and processes of change. Organization Science, 15(3), 295-309. https://doi.org/10. 1287/orsc.1040.0073

Fleishman, E. A., \& Zaccaro, S. J. (1992). Toward a taxonomy of team performance functions. In R. W. Swezey \& E. Salas (Eds.), Teams; their training and performance (pp. 31-56). Ablex.

Forgas, J. P., \& George, J. M. (2001). Affective influences on judgments and behavior in organizations: An information processing perspective. Organizational Behavior and Human Decision Processes, 86(1), 3-34. https://doi.org/10.1006/obhd.2001.2971

Friedlander, F. (1987). The ecology of work groups. In J. Lorsch (Ed.), Handbook of organizational behavior (pp. 301-314). Prentice Hall.

Gibson, C. B., \& Dibble, R. (2013). Excess may do harm: Investigating the effect of team external environment on external activities in teams. Organization Science, 24(3), 697-715. https://doi.org/10.1287/orsc. 1120.0766

Gonzalez-Mulé, E., Kim, M., \& Ryu, J. W. (2021). A meta-analytic test of multiplicative and additive models of job demands, resources, and stress. Journal of Applied Psychology, 106(9), 1391-1411. https://doi. org/10.1037/apl0000840
Grawitch, M., Munz, D., \& Kramer, T. (2003). Effects of member mood states on creative performance in temporary workgroups. Group Dynamics, 7(1), 41-54. https://doi.org/10.1037/1089-2699.7.1.41

Guinan, P. J., Cooprider, J. G., \& Faraj, S. (1998). Enabling software development team performance during requirements definition: $A$ behavioral versus technical approach. Information Systems Research, 9(2), 101-125. https://doi.org/10.1287/isre.9.2.101

Haas, M. R. (2006). Knowledge gathering, team capabilities, and project performance in challenging work environments. Management Science, 52(8), 1170-1184. https://doi.org/10.1287/mnsc.1060.0530

Hackman, J. R. (1983). A normative model of work team effectiveness. Technical report. Yale University. https://apps.dtic.mil/sti/pdfs/ ADA136398.pdf

Hackman, J. R. (1987). The design of work teams. In J. Lorsch (Ed.), Handbook of organizational behavior. Prentice-Hall.

Hakanen, J. J., Perhoniemi, R., \& Toppinen-Tanner, S. (2008). Positive gain spirals at work: From job resources to work engagement, personal initiative, and work-unit innovativeness. Journal of Vocational Behavior, 73(1), 78-91. https://doi.org/10.1016/j.jvb.2008.01.003

Halbesleben, J. R. B., Neveu, J.-P., Paustian-Underdahl, S. C., \& Westman, M. (2014). Getting to the "COR": Understanding the role of resources in conservation of resources theory. Journal of Management, 40(5), 1334-1364. https://doi.org/10.1177/0149206314527130

Hansen, M. T. (1999). The search-transfer problem: The role of weak ties in sharing knowledge across organization subunits. Administrative Science Quarterly, 44(1), 82-111. https://doi.org/10.2307/ 2667032

Hauptman, O. (1986). Influence of task type on the relationship between communication and performance: The case of software development. R\&D Management, 16(2), 127-139. https://doi.org/10.1111/j.14679310.1986.tb01166.x

Hernes, G. (1988). Real virtuality. In P. Hedström \& R. Swedberg (Eds.), Social mechanisms: An analytical approach to social theory (pp. 74-101). Cambridge University Press.

Hulsheger, U. R., Anderson, N., \& Salgado, J. F. (2009). Team-level predictors of innovation at work: A comprehensive meta-analysis spanning three decades of research. Journal of Applied Psychology, 94(5), 11281145. https://doi.org/10.1037/a0015978

James, L. R., Demaree, R. G., \& Wolf, G. (1984). Estimating within-group interrater reliability with and without response bias. Journal of Applied Psychology, 69(1), 85-98. https://doi.org/10.1037/0021-9010.69.1.85

James, L. R., Demaree, R. G., \& Wolf, G. (1993). R(WG): An assessment of within-group interrater agreement. Journal of Applied Psychology, 78(2), 306-309. https://doi.org/10.1037/0021-9010.78.2.306

Janssen, O. (2001). Fairness perceptions as a moderator in the curvilinear relationship between job demands, and job performance and job satisfaction. Academy of Management Journal, 44(5), 1039-1050. https:// doi.org/10.2307/3069447

Johnson, P. O., \& Neyman, J. (1936). Tests of certain linear hypotheses and their application to some educational problems. Statistical Research Memoirs, 1, 57-93.

Joshi, A., Pandey, N., \& Han, G. H. (2009). Bracketing team boundary spanning: An examination of task-based, team-level, and contextual antecedents. Journal of Organizational Behavior, 30(6), 731-759. https:// doi.org/10.1002/job.v30:610.1002/job.567

Kanter, R. M. (1988). When a thousand flowers bloom: Structural, collective, and social conditions for innovation in organizations. In B. M. Staw \& L. L. Cummings (Eds.), Research in organizational behavior (Vol. 10, pp. 169-211). JAI Press.

Karasek, R. A. (1979). Job demands, job decision latitude, and mental strain: Implications for job redesign. Administrative Science Quarterly, 24(2), 285-308. https://doi.org/10.2307/2392498

Katz, R. (1982). The effects of group longevity on project communication and performance. Administrative Science Quarterly, 27(1), 81-104. https://doi.org/10.2307/2392547 
Keller, R. T. (2001). Cross-functional project groups in research and new product development: Diversity, communications, job stress, and outcomes. Academy of Management Journal, 44(3), 547-555. https://doi. org/10.2307/3069369

Kianto, A. (2011). Enabling innovation in knowledge worker teams. International Journal of Learning \& Intellectual Capital, 8(1), 30-49. https://doi. org/10.1504/IJLIC.2011.037357

Knight, A. P. (2015). Mood at the midpoint: Affect and change in exploratory search over time in teams that face a deadline. Organization Science, 26(1), 99-118. https://doi.org/10.1287/orsc.2013.0866

Knight, A. P., \& Eisenkraft, N. (2015). Positive is usually good, negative is not always bad: The effects of group affect on social integration and task performance. Journal of Applied Psychology, 100(4), 1214-1227. https://doi.org/10.1037/apl0000006

Köhler, T., \& Cortina, J. M. (2019). Play it again, Sam! An analysis of constructive replication in the organizational sciences. Journal of Management, 47(2), 488-518. https://doi.org/10.1177/0149206319843985

Lee, H. W., Choi, J. N., \& Kim, S. (2018). Does gender diversity help teams constructively manage status conflict? An evolutionary perspective of status conflict, team psychological safety, and team creativity. Organizational Behavior and Human Decision Processes, 144, 187-199. https://doi.org/10.1016/j.obhdp.2017.09.005

Lewis, M. W., Welsh, M. A., Dehler, G. E., \& Green, S. G. (2002). Product development tensions: Exploring contrasting styles of project management. Academy of Management Journal, 45(3), 546-564. https://doi. org/10.5465/3069380

Loi, R., Liu, Y., Lam, L. W., \& Xu, A. J. (2016). Buffering emotional job demands: The interplay between proactive personality and team potency. Journal of Vocational Behavior, 95-96, 128-137. https://doi. org/10.1016/j.jvb.2016.08.007

MacKinnon, D. P., Lockwood, C. M., \& Williams, J. (2004). Confidence limits for the indirect effect: Distribution of the product and resampling methods. Multivariate Behavioral Research, 39(1), 99-128. https://doi.org/10.1207/s15327906mbr3901_4

Madrid, H. P., Patterson, M. G., Birdi, K. S., Leiva, P. I., \& Kausel, E. E. (2014). The role of weekly high-activated positive mood, context, and personality in innovative work behavior: A multilevel and interactional model. Journal of Organizational Behavior, 35(2), 234-256. https://doi. org/10.1002/job.1867

Madrid, H. P., Totterdell, P., Niven, K., \& Barros, E. (2016). Leader affective presence and innovation in teams. Journal of Applied Psychology, 101(5), 673-686. https://doi.org/10.1037/apl0000078

Mäkikangas, A., Bakker, A. B., Aunola, K., \& Demerouti, E. (2010). Job resources and flow at work: Modeling the relationship via latent growth curve and mixture model methodology. Journal of Occupational and Organizational Psychology, 83(3), 795-814. https://doi.org/10. 1348/096317909X476333

Marks, M. A., Mathieu, J. E., \& Zaccaro, S. J. (2001). A temporally based framework and taxonomy of team processes. Academy of Management Review, 26(3), 356-376. https://doi.org/10.5465/AMR.2001. 4845785

Marrone, J. A. (2010). Team boundary spanning: A multilevel review of past research and proposals for the future. Journal of Management, 36(4), 911-940. https://doi.org/10.1177/0149206309353945

Marrone, J. A., Tesluk, P. E., \& Carson, J. B. (2007). A multilevel investigation of antecedents and consequences of team member boundaryspanning behavior. Academy of Management Journal, 50(6), 14231439. https://doi.org/10.5465/AMJ.2007.28225967

Mathieu, J. E., Maynard, M. T., Rapp, T., \& Gilson, L. (2008). Team effectiveness 1997-2007: A review of recent advancements and a glimpse into the future. Journal of Management, 34(3), 410-476. https://doi. org/10.1177/0149206308316061

Maxwell, S. E., \& Cole, D. A. (2007). Bias in cross-sectional analyses of longitudinal mediation. Psychological Methods, 12, 23-44. https://doi.org/ 10.1037/1082-989X.12.1.23
Morgan, N. A., \& Piercy, N. F. (1998). Interactions between marketing and quality at the SBU level: Influences and outcomes. Journal of the Academy of Marketing Science, 26(3), 190-208. https://doi.org/10.1177/ 0092070398263002

Morgeson, F. P., \& Hofmann, D. A. (1999). The structure and function of collective constructs: Implications for multilevel research and theory development. Academy of Management Review, 24(2), 249-265. https://doi.org/10.2307/259081

Muthén, L. K., \& Muthén, B. O. (1998-2017). Mplus User's guide (8th ed.). Muthén \& Muthén.

Ohly, S., Sonnentag, S., Niessen, C., \& Zapf, D. (2010). Diary studies in organizational research: An introduction and some practical recommendations. Journal of Personnel Psychology, 9(2), 79-93. https://doi. org/10.1027/1866-5888/a000009

Park, S. H., \& Luo, Y. D. (2001). Guanxi and organizational dynamics: Organizational networking in Chinese firms. Strategic Management Journal, 22(5), 455-477. https://doi.org/10.1002/smj.167

Ployhart, R. E., \& Vandenberg, R. J. (2010). Longitudinal research: The theory, design, and analysis of change. Journal of Management, 36, 94120. https://doi.org/10.1177/0149206309352110

Podsakoff, N. P., LePine, J. A., \& LePine, M. A. (2007). Differential challenge stressor-hindrance stressor relationships with job attitudes, turnover intentions, turnover, and withdrawal behavior: A meta-analysis. Journal of Applied Psychology, 92(2), 438-454. https://doi.org/10. 1037/0021-9010.92.2.438

Podsakoff, P. M., MacKenzie, S. B., Lee, J. Y., \& Podsakoff, N. P. (2003). Common method biases in behavioral research: A critical review of the literature and recommended remedies. Journal of Applied Psychology, 88(5), 879-903. https://doi.org/10.1037/0021-9010.88.5.879

Porter, C., Webb, J. W., \& Gogus, C. I. (2010). When goal orientations collide: Effects of learning and performance orientation on team adaptability in response to workload imbalance. Journal of Applied Psychology, 95(5), 935-943. https://doi.org/10.1037/a0019637

Preacher, K. J., \& Hayes, A. F. (2008). Asymptotic and resampling strategies for assessing and comparing indirect effects in multiple mediator models. Behavior Research Methods, 40(3), 879-891. https://doi.org/ 10.3758/BRM.40.3.879

Prince, C., \& Salas, E. (1993). Training research for teamwork in the military aircrew. In E. L. Wiener, B. G. Kanki, \& R. L. Helmreich (Eds.), Cockpit research management (pp. 337-366). Academic Press.

Rai, A. (2018). Differential relationship of challenge and hindrance demands with employee engagement. International Journal of Sociology and Social Policy, 38(9/10), 887-906. https://doi.org/10.1108/IJSSP12-2017-0174

Reagans, R., \& Zuckerman, E. W. (2001). Networks, diversity, and productivity: The social capital of corporate R\&D teams. Organization Science, 12(4), 502-517. https://doi.org/10.1287/orsc.12.4.502.10637

Rhee, S. Y. (2006). Shared emotions and group effectiveness: The role of broadening-and-building interactions. In Proceedings of the Sixty-fifth Annual Meeting of the Academy of Management (pp. 1-40), August 1, 2006:1 B1-B6). https://doi.org/10.5465/AMBPP.2006.22898617

Richter, A. W., West, M. A., van Dick, R., \& Dawson, J. F. (2006). Boundary spanners' identification, intergroup contact, and effective intergroup relations. Academy of Management Journal, 49(6), 1252-1269. https:// doi.org/10.5465/AMJ.2006.23478720

Russell, J. A. (1980). A circumplex model of affect. Journal of Personality and Social Psychology, 39(6), 1161-1178. https://doi.org/10.1037/h0077714

Sacramento, C. A., Fay, D., \& West, M. A. (2013). Workplace duties or opportunities? Challenge stressors, regulatory focus, and creativity. Organizational Behavior and Human Decision Processes, 121(2), 141157. https://doi.org/10.1016/j.obhdp.2013.01.008

Salanova, M., \& Schaufeli, W. B. (2008). A cross-national study of work engagement as a mediator between job resources and proactive behaviour. International Journal of Human Resource Management, 19(1), 116-131. https://doi.org/10.1080/09585190701763982 
Sawyer, S., Guinan, P. J., \& Cooprider, J. (2010). Social interactions of information systems development teams: A performance perspective. Information Systems Journal, 20(1), 81-107. https://doi.org/10.1111/j. 1365-2575.2008.00311.x

Schaufeli, W. B., \& Bakker, A. B. (2004). Job demands, job resources, and their relationship with burnout and engagement: A multi-sample study. Journal of Organizational Behavior, 25(3), 293-315. https://doi.org/10. 1002/job.248

Schaufeli, W. B., Bakker, A. B., \& Salanova, M. (2006). The measurement of work engagement with a short questionnaire-A cross-national study. Educational and Psychological Measurement, 66(4), 701-716. https:// doi.org/10.1177/0013164405282471

Schaufeli, W. B., \& Taris, T. (2014). A critical review of the job demandsresources model: Implications for improving work and health. In G. F. Bauer \& O. Hämmig (Eds.), Bridging occupational, organizational and public health: A transdisciplinary approach. Springer. https://doi.org/10. 1007/978-94-007-5640-3_4

Scott, W. R. (1998). Organizations: Rational, natural, and open systems. Prentice Hall.

Shaw, J. B. (2004). The development and analysis of a measure of group faultlines. Organizational Research Methods, 7(1), 66-100. https://doi. org/10.1177/1094428103259562

Sherman, J. D., \& Keller, R. T. (2010). Suboptimal assessment of interunit task interdependence: Modes of integration and information processing for coordination performance. Organization Science, 22(1), 245-261. https://doi.org/10.1287/orsc.1090.0506

Shirom, A. (2003). Job-related burnout: A review. In J. C. Quick \& L. E. Tetrick (Eds.), Handbook of occupational health psychology (pp. 245264). American Psychological Association. https://doi.org/10.1037/ 10474-012

Sleep, S., Bharadwaj, S., \& Lam, S. K. (2015). Walking a tightrope: The joint impact of customer and within-firm boundary spanning activities on perceived customer satisfaction and team performance. Journal of the Academy of Marketing Science, 43(4), 472-489. https://doi.org/10. 1007/S11747-014-0395-4

Somech, A., \& Khalaili, A. (2014). Team boundary activity: Its mediating role in the relationship between structural conditions and team innovation. Group \& Organization Management, 39(3), 274-299. https:// doi.org/10.1177/1059601114525437

Sung, S. Y., \& Choi, J. N. (2012). Effects of team knowledge management on the creativity and financial performance of organizational teams. Organizational Behavior and Human Decision Processes, 118(1), 4-13. https://doi.org/10.1016/j.obhdp.2012.01.001

Sutton, R. I., \& Staw, B. M. (1995). What theory is not. Administrative Science Quarterly, 40(3), 371-384. https://doi.org/10.2307/2393788

Thatcher, S. B., \& Patel, P. C. (2012). Group faultlines: A review, integration, and guide to future research. Journal of Management, 38(3), 969-1009. https://doi.org/10.1177/0149206311426187

Theorell, T., \& Karasek, R. A. (1996). Current issues relating to psychosocial job strain and cardiovascular disease research. Journal of Occupational Health Psychology, 1(1), 9-26. https://doi.org/10.1037/ 1076-8998.1.1.9

Thompson, J. D. (1967). Organizations in action. McGraw Hill.

Tu, Y., Lu, X., Choi, J. N., \& Guo, W. (2019). Ethical leadership and teamlevel creativity: Mediation of psychological safety climate and moderation of supervisor support for creativity. Journal of Business Ethics, 159(2), 551-565. https://doi.org/10.1007/s10551-018-3839-9

Van Katwyk, P. T., Fox, S., Spector, P. E., \& Kelloway, E. K. (2000). Using the Job-Related Affective Well-Being Scale (JAWS) to investigate affective responses to work stressors. Journal of Occupational Health Psychology, 5(2), 219-230. https://doi.org/10.1037/1076-8998.5. 2.219
West, M. A., \& Anderson, N. R. (1996). Innovation in top management teams. Journal of Applied Psychology, 81(6), 680-693. https://doi.org/ 10.1037/0021-9010.81.6.680

West, M. A., \& Wallace, M. (1991). Innovation in health care teams European Journal of Social Psychology, 21(4), 303-315. https://doi.org/ 10.1002/ejsp.2420210404

Xanthopoulou, D., Bakker, A. B., Demerouti, E., \& Schaufeli, W. B. (2009). Work engagement and financial returns: A diary study on the role of job and personal resources. Journal of Occupational and Organizational Psychology, 82(1), 183-200. https://doi.org/10.1348/ $096317908 \times 285633$

Yan, A. M., \& Louis, M. R. (1999). The migration of organizational functions to the work unit level: Buffering, spanning, and bringing up boundaries. Human Relations, 52(1), 25-47. https://doi.org/10.1023/A: 1016968332082

\section{AUTHOR BIOGRAPHIES}

Ulrich Leicht-Deobald is a postdoc at the Institute for Business Ethics at the University of St.Gallen. He received his PhD from the University of St.Gallen. His research focuses on new ways of working, in particular on intraorganizational collaboration and the use of $\mathrm{Al}$ in $\mathrm{HR}$ management.

Chak Fu Lam is an associate professor of management at the City University of Hong Kong. He received his PhD from University of Michigan's Ross School of Business. His research explores the antecedents and consequences of employee voice behavior and well-being at work.

Heike Bruch is a professor of Leadership at the University of St. Gallen. She received her PhD from the University of Hannover. Her research focuses on leadership, organizational energy, and new forms of work.

Florian Kunze is a professor for Organizational Studies at the University of Konstanz. He received his PhD from the University of St.Gallen. His research evolves around the topics of team and organizational diversity processes, aging in organizations, and effective leadership behaviors.

Wen $\mathbf{W u}$ is an associate professor at the School of Economics and Management, Beijing Jiaotong University. He received his $\mathrm{PhD}$ from Beijing Jiaotong University. His research focuses on newcomer socialization, voice behavior, and team creativity.

How to cite this article: Leicht-Deobald, U., Lam, C. F., Bruch, H., Kunze, F., \& Wu, W. (2022). Team boundary work and team workload demands: Their interactive effect on team vigor and team effectiveness. Human Resource Management, 1-24. https://doi.org/10.1002/hrm.22104 


\section{APPENDIX A}

TAB LE A1 Path model results without controls (Study 1)

\begin{tabular}{|c|c|c|c|c|c|c|c|c|}
\hline Predictor & \multicolumn{2}{|c|}{$\begin{array}{l}\text { Model } 9 \\
\text { Mediation-only }\end{array}$} & \multicolumn{2}{|c|}{$\begin{array}{l}\text { Model } 10 \\
\text { Moderated mediation }\end{array}$} & \multicolumn{2}{|c|}{$\begin{array}{l}\text { Model } 11 \\
\text { Moderated mediation }\end{array}$} & \multicolumn{2}{|c|}{$\begin{array}{l}\text { Model } 12 \\
\text { Moderated mediation } \\
\beta\end{array}$} \\
\hline \multicolumn{9}{|l|}{ Mediator variable: Team vigor } \\
\hline Boundary spanning ( $\mathrm{H} 1 \mathrm{a})$ & $0.26^{* * *}$ & $(0.07,0.000)$ & $0.29^{* *}$ & $(0.08,0.001)$ & $0.29^{* * *}$ & $(0.08,0.000)$ & $0.29^{* * *}$ & $(0.08,0.001)$ \\
\hline Boundary buffering ( $\mathrm{H} 1 \mathrm{~b})$ & $0.25^{*}$ & $(0.10, .015)$ & $0.23^{*}$ & $(0.11,0.040)$ & $-0.24^{*}$ & $(0.10,0.016)$ & $-0.23^{*}$ & $(0.11,0.033)$ \\
\hline Team workload demands & 0.08 & $(0.08,0.322)$ & 0.05 & $(0.08,0.564)$ & 0.13 & $(0.08,0.112)$ & 0.07 & $(0.09,0.409)$ \\
\hline $\begin{array}{l}\text { Boundary buffering } \times \text { team job } \\
\text { demands }(\mathrm{H} 2 \mathrm{~b})\end{array}$ & & & & & $0.22^{* *}$ & $(0.07,0.001)$ & 0.09 & $(0.10,0.332)$ \\
\hline$R^{2}$ & 0.15 & & 0.22 & & 0.20 & & 0.23 & \\
\hline$\Delta R^{2}$ interaction term & & & $0.07^{* *}$ & & $0.04^{*}$ & & $0.08^{* *}$ & \\
\hline Team workload demands & -0.03 & $(0.13,0.820)$ & -0.02 & $(0.13,0.890)$ & -0.05 & $(0.12,0.689)$ & -0.03 & $(0.12,0.840)$ \\
\hline $\begin{array}{l}\text { Boundary spanning } \times \text { team job } \\
\text { demands }\end{array}$ & & & -0.12 & $(0.10,0.240)$ & & & -0.21 & $(0.36,0.561)$ \\
\hline $\begin{array}{l}\text { Boundary buffering } \times \text { team job } \\
\text { demands }\end{array}$ & & & & & -0.13 & $(0.15,0.405)$ & -0.05 & $(0.25,0.848)$ \\
\hline Team vigor ( $\mathrm{H} 3 \mathrm{a})$ & $0.22^{*}$ & $(0.10, .019)$ & $0.26^{*}$ & $(0.11,0.017)$ & $-0.24^{* *}$ & $(0.11,0.030)$ & $-0.26^{*}$ & $(0.11,0.026)$ \\
\hline$R^{2}$ & 0.05 & & 0.06 & & 0.06 & & 0.06 & \\
\hline
\end{tabular}

Note: Standardized path coefficients are reported. Values in parentheses are the standard errors and the exact $p$ values.

${ }^{\dagger} p<0.10 ;{ }^{*} p<0.05 ;{ }^{* *} p<0.01 ;{ }^{* * *} p<0.001$ (two-tailed).

TABLE A2 Confirmatory factor analyses results (Study 1)

\begin{tabular}{|c|c|c|c|c|c|c|c|c|}
\hline Model & $\chi^{2}$ & df & $\Delta \chi^{2}$ & $\Delta \mathbf{d f}$ & CFI & TLI & RMSEA & SRMR \\
\hline Baseline model: five factors & 218.71 & 125 & - & - & 0.89 & 0.86 & 0.09 & 0.08 \\
\hline Model 1: four factors (combining BS and BB) & 262.74 & 129 & $+43.03^{* * *}$ & 4 & 0.84 & 0.81 & 0.11 & 0.10 \\
\hline Model 2: three factors (combining BS, BB, and TD) & 429.16 & 132 & $+210.45^{* * *}$ & 7 & 0.65 & 0.59 & 0.16 & 0.12 \\
\hline $\begin{array}{l}\text { Model 3: two factors (combining BS, BB, and IN; } \\
\text { TD and VIG) }\end{array}$ & 447.19 & 134 & $+228.48^{* * *}$ & 9 & 0.63 & 0.58 & 0.16 & 0.17 \\
\hline Model 5: one factor (combining all) & 599.47 & 135 & $+380.76^{* * *}$ & 10 & 0.45 & 0.38 & 0.20 & 0.16 \\
\hline
\end{tabular}

Note: To form three parcels of items as indicators of team innovation, we averaged the three items of each sub-dimension, as recommended by Bagozzi and Edwards (1998). Each alternative model is compared to the baseline model.

Abbreviations: BB, boundary buffering; BS, boundary spanning; CFI, comparative fit index; df, degree of freedom; IN, team innovation; RMSEA, root mean square error of approximation; SRMR, standardized root mean square residual; TD, team workload demands; TLI, Tucker-Lewis index; VIG, team vigor, . ${ }^{* * *} p<0.001$ 
TABLE A3 Path model results without controls (Study 2)

\begin{tabular}{|c|c|c|c|c|c|c|c|c|}
\hline \multirow{2}{*}{$\begin{array}{l}\text { Predictor } \\
\text { Mediator variable: team vigor }\end{array}$} & \multicolumn{2}{|c|}{$\begin{array}{l}\text { Model } 13 \\
\text { Mediation-only } \\
\beta\end{array}$} & \multicolumn{2}{|c|}{$\begin{array}{l}\text { Model } 14 \\
\text { Moderated mediation } \\
\beta\end{array}$} & \multicolumn{2}{|c|}{$\begin{array}{l}\text { Model } 15 \\
\text { Moderated mediation } \\
\beta\end{array}$} & \multicolumn{2}{|c|}{$\begin{array}{l}\text { Model } 16 \\
\text { Moderated mediation } \\
\beta\end{array}$} \\
\hline & & & & & & & & \\
\hline Boundary spanning $(\mathrm{H} 1 \mathrm{a})$ & $0.25^{* *}$ & $(0.08,0.002)$ & $0-.25^{* *}$ & $(0.07,0.001)$ & $0.27^{* *}$ & $(0.08,0.001)$ & $0.25^{* *}$ & $(0.08,0.001)$ \\
\hline Boundary buffering ( $\mathrm{H} 1 \mathrm{~b})$ & $0.39^{* * *}$ & $(0.08,0.000)$ & $0.42^{* * *}$ & $(0.08,0.000)$ & $0.38^{* * *}$ & $(0.08,0.000)$ & $0.41^{* * *}$ & $(0.08,0.000)$ \\
\hline $\begin{array}{l}\text { Boundary buffering } \times \text { team job } \\
\text { demands }(\mathrm{H} 2 \mathrm{~b})\end{array}$ & & & & & $-0.13 \dagger$ & $(0.07,0.073)$ & 0.02 & $(0.08,0.859)$ \\
\hline$R^{2}$ & 0.31 & & 0.35 & & 0.32 & & 0.35 & \\
\hline$\Delta R^{2}$ interaction term & & & $0.04^{*}$ & & $0.01 \dagger$ & & $0.04^{*}$ & \\
\hline $\begin{array}{l}\text { Boundary spanning } \times \text { team job } \\
\text { demands }\end{array}$ & & & -0.36 & $(0.27,0.177)$ & & & -0.11 & $(0.11,0.320)$ \\
\hline $\begin{array}{l}\text { Boundary buffering } \times \text { team job } \\
\text { demands }\end{array}$ & & & & & -0.20 & $(0.21,0.351)$ & -0.02 & $(0.10,0.844)$ \\
\hline Team vigor $(\mathrm{H} 3 \mathrm{~b})$ & $0.25^{*}$ & $(0.10,0.011)$ & $0.30^{* *}$ & $(0.11,0.006)$ & $0.28^{* *}$ & $(0.11,0.010)$ & $0.28^{* *}$ & $(0.10,0.005)$ \\
\hline$R^{2}$ & 0.10 & & 0.11 & & 0.10 & & 0.11 & \\
\hline
\end{tabular}

Note: Standardized path coefficients are reported. Values in parentheses are the standard errors and the exact $p$ values.

${ }^{\dagger} p<0.10 ;{ }^{*} p<0.05 ;{ }^{* *} p<0.01 ;{ }^{* * *} p<0.001$ (two-tailed).

TAB LE A4 Confirmatory factor analyses results (Study 2)

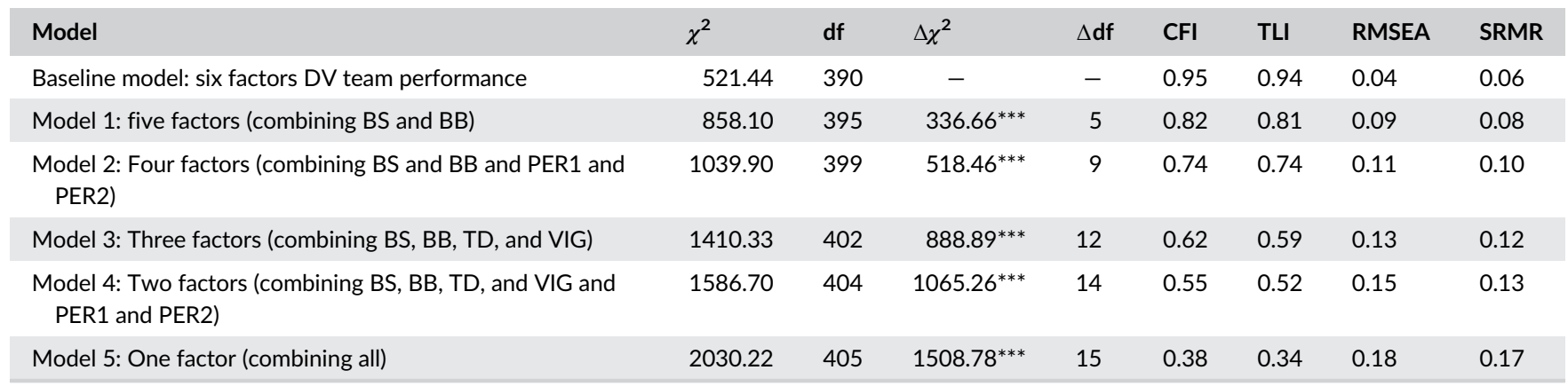

Note: Each alternative model is compared to the baseline model.

Abbreviations: BB, boundary buffering; BS, boundary-spanning; CFI, comparative fit index; df, degree of freedom; PER1, team performance (Time 1), PER2, team performance (Time 2); RMSEA, root mean square error of approximation; SRMR, standardized root mean square residual; TD, team workload demands; TLI, Tucker-Lewis index; VIG, team vigor.

${ }^{* * *} p<0.001$. 